\title{
Optimizing Molecular-Targeted Therapies in Ovarian Cancer: The Renewed Surge of Interest in Ovarian Cancer Biomarkers and Cell Signaling Pathways
}

\author{
Donavon Hiss \\ Molecular Oncology Research Laboratory, Department of Medical BioSciences, University of the Western Cape, \\ Bellville 7535, South Africa \\ Correspondence should be addressed to Donavon Hiss, dhiss@uwc.ac.za
}

Received 15 September 2011; Accepted 24 November 2011

Academic Editor: Kentaro Nakayama

Copyright ( $) 2012$ Donavon Hiss. This is an open access article distributed under the Creative Commons Attribution License, which permits unrestricted use, distribution, and reproduction in any medium, provided the original work is properly cited.

\begin{abstract}
The hallmarks of ovarian cancer encompass the development of resistance, disease recurrence and poor prognosis. Ovarian cancer cells express gene signatures which pose significant challenges for cancer drug development, therapeutics, prevention and management. Despite enhancements in contemporary tumor debulking surgery, tentative combination regimens and abdominal radiation which can achieve beneficial response rates, the majority of ovarian cancer patients not only experience adverse effects, but also eventually relapse. Therefore, additional therapeutic possibilities need to be explored to minimize adverse events and prolong progression-free and overall response rates in ovarian cancer patients. Currently, a revival in cancer drug discovery is devoted to identifying diagnostic and prognostic ovarian cancer biomarkers. However, the sensitivity and reliability of such biomarkers may be complicated by mutations in the BRCA1 or BRCA2 genes, diverse genetic risk factors, unidentified initiation and progression elements, molecular tumor heterogeneity and disease staging. There is thus a dire need to expand existing ovarian cancer therapies with broad-spectrum and individualized molecular targeted approaches. The aim of this review is to profile recent developments in our understanding of the interrelationships among selected ovarian tumor biomarkers, heterogeneous expression signatures and related molecular signal transduction pathways, and their translation into more efficacious targeted treatment rationales.
\end{abstract}

\section{Introduction}

Ovarian cancer is the major cause of gynecological cancer deaths worldwide [1-6]. It is widely accepted that the distinctive genotypic and phenotypic characteristics of ovarian cancer not only promote its metastatic potential but are also responsible for the development of resistance to conventional modes of cancer therapy, disease recurrence, and poor prognosis [2, 4, 7-19]. In particular, epithelial ovarian cancer (EOC) presents a considerable impediment to successful treatment outcome because of its propensity to embark on a program of epithelial-to-mesenchymal transition (EMT), a transdifferentiation process that is almost invariably associated with tumor progression and invasiveness [2, 15, 19-24].

Furthermore, self-renewing ovarian cancer stem cells (OCSCs) or ovarian cancer-initiating cells (OCICs), as well as mesenchymal stem cells (MSCs), have been implicated in ovarian tumorigenesis, intra- and extraperitoneal metastases, and chemoresistance [2, 19, 25-27]. Since cancer stem cells (CSCs) are predominantly quiescent, have upregulated DNA repair capacity, are noncommittal to apoptosis, and overexpress ATP-binding cassette (ABC) drug efflux transporters, for example, ABCG1 (MDR1/P-glycoprotein/Pgp), ABCG2, and breast cancer resistance protein (BCRP), and a profusion of cancer gene signatures, they sustain the succession of clonal tumor cell proliferation and repopulation in the tumor microenvironment [2, 22, 25, 26, 28-38]. Many CSC-derived or EMT-induced tumors, including ovarian cancer, also express this aggressive, malignant, and multidrug resistance (MDR) phenotype and other tumor prosurvival repertoires which pose significant challenges for cancer drug development, therapeutics, prevention, and management [2, 19-22, 28, 33, 34, 39]. 
The optimal management modality for ovarian cancer includes histopathological diagnosis and staging, debulking (surgical resection) of the tumor, and several cycles of intravenous (IV) or intraperitoneal (IP) chemotherapy with carboplatin and paclitaxel at maximum tolerated doses (MTDs), followed by maintenance or salvage treatments, in cases of disease recurrence [3, 12, 15, 40, 41]. Although refinements in tumor ablation procedures and IP combination chemotherapy with carboplatin and paclitaxel can achieve beneficial response rates, for example, median progression-free survival (PFS) range of 16 to 21 months and median overall survival (OS) range of 24 to 60 months, most patients with advanced disease ultimately relapse [15, $23,40,42-46]$. Likewise, the majority of contemporary or tentative regimens of more than two cytotoxic drugs as well as low-dose chemosensitizing abdominal radiation have not yielded radically improved efficacy or significantly reduced adverse effects over the dual combination of carboplatin and paclitaxel, suggesting that other therapeutic avenues need to be explored to prolong PFS and OS rates in ovarian cancer patients [23, 39, 41, 47-55].

Recently, there has been a resurgence of efforts to identify ovarian cancer biomarkers for use in initial detection, staging, disease prognosis, molecular therapeutic targeting, and individualized clinical management of patients $[14,56-$ 73]. Nonetheless, the sensitivity and reliability of ovarian cancer biomarkers may be confounded by several characteristics of the disease such as mutations in the BRCA1 or $B R C A 2$ genes and their arcane absence in sporadic ovarian cancer, diverse genetic risk factors, unidentified initiation and progression elements, molecular tumor heterogeneity, and transition time between different stages of the disease. Correspondingly, the lack of a one-fit-all (i.e., highly sensitive and specific) biomarker for different histotypes of ovarian cancer-for example, EOC can be classified into four distinct histotypes: fallopian tube (serous), endometrium (endometrioid), endocervix (mucinous), or nests within the vagina (clear cell), coupled with differential overexpression of homeobox (Hox) genes-suggests that combination panels of biomarkers may offer greater diagnostic and prognostic probability $[2,12,71,73-75]$. There is a critical need to develop broad-spectrum as well as individualized moleculartargeted therapies for ovarian cancers. Ingenious approaches are currently being applied to precisely map signal transduction pathways and target key molecular role players that direct ovarian tumor sensitivity and resistance to therapy and OS rates in patients. These include improved ultrasound and imaging technologies, molecular genetic analysis, as well as genomic, transcriptomic, and proteomic profiling of novel ovarian tumor biomarkers $[2,7,14,16,56,61,72,76-$ $94]$. In view of the complexities and variable response rates experienced with ovarian cancer patients clinically, the aim of this review is to outline recent developments in our understanding of the interrelationships among selected ovarian tumor biomarkers, heterogeneous expression signatures and related molecular signal transduction pathways, and their translation into futuristic as well as more efficacious targeted treatment rationales.

\section{The Molecular Therapeutic Targeting Paradigm}

The recurrence of ovarian tumors implies resistance to therapy regardless of encouraging response rates to cytoreductive surgery and combination chemotherapy, and most patients who relapse will eventually succumb to the disease $[3,15$, $43,44,65,95-98]$. The poor prognosis in ovarian cancer patients may be broadly ascribed to distinct tumor histotypes or heterogeneity, disparate genomic expression profiles, and strikingly different molecular abnormalities $[2,12,16-$ $18,39,56,69,99-104]$. Thus, the likelihood of ovarian cancer recurrence and resistance to therapy warrants serious alternative or complementary strategies to conventional oncologic modalities [1-4, 23, 42, 96, 105-107]. The potential for molecular-targeted therapy of ovarian cancers is increasingly being recognized and empirically validated [61, $108,109]$. Molecular therapeutic targeting is an approach that exploits specific hallmarks of cancers and the tumor microenvironment and their rationalization into clinically relevant and potent anticancer drugs with fewer side effects $[1,2,23,37,39,110-118]$. Moreover, the application and exploitation of the dynamics of molecular-targeted system networks hold great promise for the design of personalized cancer therapies $[119,120]$. This review provides a concise insight into recent advances in the molecular mechanisms of signal transduction pathways, the development MDR, DNA repair mechanisms, and tumor biomarkers of prognostic indicators and their therapeutic potential as translational targets in ovarian cancer.

\section{Ovarian Cancer Biomarkers and Cell Signaling Pathways}

A number of reliable, complementary, or potential diagnostic and prognostic biomarkers have been reported to be overexpressed or deregulated in different types of ovarian cancer. These will be considered in Sections 3 and 4.

3.1. Breast Cancer 1 and $2(B R C A 1 / 2)$ Oncogenes. Ovarian cancers are associated with breast cancer 1 (BRCA1) and $B R C A 2$ oncogenes, variously inherited as germline mutations [121-124]. Wild-type BRCA1/2 genes are critical for DNA repair by the homologous recombination (HR) pathway-hence their deletion causes genomic instability and predisposes affected females to familial breast and ovarian cancers [103, 104, 125-127]. Ovarian cancers with mutated $B R C A 1 / 2$ genes are particularly sensitive to agents that cause DNA double strand breaks (DSBs) and DNA interstrand cross-links, like the platinum compounds (e.g., cisplatin and carboplatin) and poly(ADP-ribose) polymerase (PARP) inhibitors (e.g., olaparib, iniparib, veliparib) [128132]. It is conceivable, therefore, that secondary or reversion mutations of the BRCA1/2 genes, through multiple complex mechanisms, may favor DNA repair by HR and increase tumor cell survival and so trigger resistance to these compounds [133-138]. 
In addition, upregulation of $A B C B 1$ genes encoding the P-glycoprotein drug efflux pump has been found to be responsible for acquired resistance in a genetically engineered mouse model (GEMM) for BRCA1-associated breast cancer, following prolonged exposure to olaparib [139]. Such resistance mechanisms need to be demarcated in order to realize the full potential of molecular targeting of BRCA1/2 mutations in ovarian cancer $[140,141]$. Nonetheless, a recent phase II clinical trial with orally active olaparib in women with confirmed genetic BRCA1/2 mutations and recurrent measurable ovarian cancer has provided tangible proof of concept of the efficacy and tolerability of molecularly targeted treatment with PARP inhibitors, and validated $B R C A 1 / 2$ mutations as biomarkers for predicting responses of ovarian cancer patients to PARP inhibition [142]. Several other reports have, in the context of $\mathrm{BRCA1}^{-/-}$ovarian cancers and their sensitivity to small molecule PARP inhibitors, presented preclinical and clinical evidence that the concept of synthetic lethality which defines a condition whereby two mutations, each with viable phenotypes, produce a lethal phenotype when they are combined can thus be exploited as a molecular-targeted strategy $[133,135,143-147]$.

\subsection{Vascular Endothelial Growth Factor (VEGF) and Its Recep-} tor (VEGFR). Tumor neovascularization or angiogenesis, a process dictated by complex cellular pathways that fine-tune proangiogenic and antiangiogenic factors (i.e., an angiogenic switch) in the tumor microenvironment, allows cancers to develop new blood vessels for nutrient and oxygen supply, elimination of metabolic waste products, growth, acquisition of an invasive phenotype, and metastastic spread [148-153]. Vascular endothelial growth factor (VEGF) and its receptor (VEGFR) occupy a position of prominence in angiogenesis signaling in normal ovarian physiology and in ovarian cancer progression $[1,2,4,15,23,65,114,154-156]$. Therefore, inhibition of the angiogenesis signal transduction pathway via its ligands and receptors in ovarian cancers represents a perfectly cogent molecular targeting strategy $[1,4,95,98$, $113,153,154,157]$. VEGF has long been recognized as a biomarker for predicting ovarian cancer patient responses to VEGF and other therapies and may as well have applications in formulating individualized therapies $[4,71,72,158-$ 161]. Inhibitors of the VEGF pathway include bevacizumab (a humanized antibody that targets the ligand VEGF) and VEGF-trap (aflibercept, a high-affinity VEGFR decoy fusion protein that binds and inactivates VEGF and other ligands) $[1,3,51,95,98,114,162,163]$.

Besides blocking the VEGF pathway with VEGF antibodies, the angiogenic pathway can be targeted with small molecule VEGFR tyrosine kinase inhibitors (TKIs) - those currently used in ovarian cancer include, sorafenib, sunitinib cediranib, vandetanib, and intedanib (BIBF 1120) [7, 15, $65,153,154,162,164-166]$. Since multiple ligands and their receptors are involved in neovascularization, including platelet-derived growth factor (PDGF/R), epidermal growth factor $(E G F R / R)$, placenta growth factor $(\mathrm{PlGF} / \mathrm{R})$, KIT, fibroblast growth factor (FGF/R), and hepatocyte growth factor $(\mathrm{HGF} / \mathrm{R})$, resistance to single antiangiogenic drugs may occur in ovarian cancer patients, blocking such alternative pathways with rational drug combinations that have cross-specificity would be an appropriate molecular targeting strategy $[1,4,15,23,114,148,150,153,156,167-170]$.

3.3. The EGFR/ErbB Family of Receptor Tyrosine Kinases. In humans, the epidermal growth factor receptor EGFR/ErbB family of receptor tyrosine kinases (RTKs) comprises four members: EGFR/ErbB1/HER-1, ErbB2/Neu/HER-2, ErbB3/HER-3, and ErbB4/HER-4 [171, 172]. ErbB2 lacks ligand-binding capacity because its ectodomain is fixed and in an unfolded conformation, but it is the preferred ally for heterodimerization with EGFR to increase the duration and intensity of the signal triggered by high-affinity ligand binding to EGFR. Thus, ErbB2 is an amplifier of the ErbB signaling network [171]. Aberrant coexpression and collaboration of EGFR and ErbB2 is widespread in cancers and has been associated with poor prognosis [172-175]. Therefore, EGFR is deemed to be a useful biomarker for ovarian cancers $[1,2,4,61,176,177]$. In ovarian cancers, mutant or isoforms of EGFR RTKs transactivate signaling transduction cascades such as PI3K/AKT and Ras/Raf/MEK/MAPK/ERK that result in diverse effects, including cell proliferation, dedifferentiation, adhesion, migration, invasion, angiogenesis, and apoptosis evasion [177-183]. Accepted tenets of molecular targeting of EGFR signaling in ovarian and non-ovarian cancers encompass small molecule TKIs (e.g., erlotinib, gefitinib), ATP-binding site inhibitors (e.g., CI1033), anti-EGFR/ErbB2monoclonal antibodies (e.g., matuzumab, pertuzumab, cetuximab, trastuzumab), and multikinase inhibitors (e.g., vandetanib, sorafenib) [164, 166, 174, 184-194].

A recent phase II trial in women with predominantly platinum-resistant recurrent ovarian cancer concluded that vandetanib, a multikinase inhibitor designed to perturb both angiogenesis (i.e., VEGFR) and tumor cell growth (i.e., EGFR), did not produce translational clinical benefit since the drug inhibited EGFR and AKT levels in tumor biopsies, but had no effect on VEGFR [164]. Likewise, EGFR gene mutations and EGFR protein expression do not necessarily correlate with clinical outcome [182, 195-197]. Previous phase II clinical studies with imatinib and gefitinib in patients with refractory or recurrent EOC suggested that although these agents have marginal benefits as monotherapies in EOC, their ability to modulate molecular targets (e.g., EGFR, c-Kit, PDGFR, ERK, AKT) and demonstrate proof of concept corroborates their applicability in combinatorial molecular therapeutics $[198,199]$. A number of reports have reinforced the notion that inhibition of a single transduction pathway may be insufficient since activation of alternative signaling cascades may conceal efficacy, and that it would be more advantageous to target integrated cancer signals, for example, VEGFR- and EGFR-interdependent pathways [170] and heparin-binding epidermal growth factor-like growth factor (HB-EGF) [200, 201]. Remarkably also, the mammalian target of rapamycin (mTOR) is a central intracellular kinase that not only orchestrates proliferation, survival, and angiogenic pathways, but has also been linked to resistance 
to EGFR antagonists, and thus mTOR inhibition could be explored to interfere with tumor growth and expansion at multiple levels [4, 83, 84, 92, 159, 170, 202-205]. Another multiple molecular targeting platform is provided by EGFRinduced EMT in EOC, possibly via mechanisms that incorporate estrogen signaling, E-cadherin downregulation and expression of matrix metalloproteinase-9 (MMP-9), and Snail transcription family members (SNAIL and SLUG) [79, 206, 207]. Additionally, oncolytic viruses engineered to deliver anti-EGFR antibodies to intraperitoneal ovarian cancer cells show great potential as a future gene therapeutic focus [208]. Irrespective of the prospects for molecular targeting of EGFR RTKs in ovarian cancer, resistance to EGFR inhibitors and unwanted adverse events in ovarian and non-ovarian tumors are major clinical concerns that need to be circumvented [16, 166, 174, 191, 209, 210].

3.4. Mucin 16 (MUC16) and Lewis X Mucin Determinant (OVX1). The role of mucins in epithelial cancer, including ovarian cancer, pathogenesis is well established [211-213]. Mucin 16 (MUC16)_also called carcinoma antigen 125 (CA125) - is arguably the most consistently used biomarker for ovarian cancer $[58,59,61,64,72,73,211,214-$ 221]. MUC16 is overexpressed in EOC and correlates with decreased E-cadherin, elevated $\mathrm{N}$-cadherin and vimentin levels, and heightened invasivesness, tumorigenesis, tumor cell proliferation, and metastases, as confirmed by MUC16 knockdown which completely abolished the development of subcutaneous tumors in nude mice [222]. Interestingly, the C-terminal domain of MUC16 promotes cisplatin resistance and MUC16 selectively modulates the sensitivity of EOC cells to DNA-damaging drugs such as cyclophosphamide, doxorubicin and etoposide, effects validated by downregulation of cell surface MUC16 [223]. The strong interaction between MUC16 and mesothelin, a glycosylphosphatidylinositol- (GPI-) anchored glycoprotein, promotes cell adhesion and peritoneal metastasis of ovarian cancer cells $[224,225]$. Furthermore, MUC16 suppresses natural killer (NK) cell-induced cytolysis in EOC patients, indicating that it compromises immune-mediated tumor surveillance and destruction [226]. In preclinical and clinical studies, antibodies and vaccines directed against mucins, evaluated for their potential to delay or limit the spread of tumor cells, produced significant survival benefits [211, 227-229]. The usefulness of MUC16 as a target antigen in ovarian carcinomas is hampered by cleavage and secretion of its extracellular domain. However, a recent study has shown that the introduction of a gene encoding a chimeric antigen receptor (CAR) targeted to the retained extracellular fraction (MUC-CD) and its retroviral transduction into human T cells specifically targets and lyses MUC-CD ${ }^{+}$tumor cells and may thus signify an innovative design to adoptive immunotherapy of cancer [230-232]. In view of the previous assertions, MUC16 needs to be probed for its plausibility as a molecular target in the immunotherapy of ovarian cancers $[233,234]$.

MUC16 is used along with multiple serum biomarkers for the early detection and screening of ovarian cancer [235]. One such biomarker is the Lewis $\mathrm{X}$ mucin determinant
(OVX1) which is increased in the majority of patients with EOC [59, 71, 72, 125, 218, 221, 236-238]. Monoclonal antibodies to OVX1 are internalized by ovarian cancer cell lines in vitro and may prove useful in the molecular targeting of this neoplasm with conjugated antibodies and immunotoxins [232, 238-241]. Curiously, alterations of the sugar moieties of the glycosylated Lewis $\mathrm{X}$ and Lewis $\mathrm{Y}$ antigens are frequent in epithelial ovarian cancers and, besides having obvious prognostic implications, may be prime arbiters along with extracellular matrix component interactions (e.g., $\beta$-integrin/fibronectin, CA125/mesothelin, CD44/hyaluronan) in CD44-mediated adhesion and peritoneal spreading (metastasis) of ovarian cancer cells [242]. These mechanisms should be explored as a molecular targeting principle in ovarian cancers.

3.5. The IL-6R-JAK-STAT3 Axis and Nuclear Factor Kappa$B(N F-\kappa B)$. The upregulation of several proinflammatory cytokines in ovarian cancers confirms a link between inflammation and immunogenic-tumor microenvironment interactions in the increased risk of ovarian tumor initiation and progression [243-251]. IL-6 is a proinflammatory cytokine that modulates pleiotropic cellular and immune responses. Binding of the ligand, IL- 6 , to the $\alpha$-subunit of its receptor (IL-6R) results in the formation of a heterodimeric complex (IL-6R/gp130) which activates Janus kinase (JAK) and various downstream effectors such as signal transducer and activator of transcription 3 (STAT3), SHP-2/Ras, mitogen-activated protein kinase (MAPK), and phosphatidylinositol-triphosphate kinase PI3K/Akt, critical for cell proliferation, apoptosis evasion and survival, drug resistance, and inactivation of tumor suppressors [252258]. STAT3 is also activated by growth factor receptor signaling, including EGFR, HER2, VEGFR, PDGFR, IGFR, and FGFR [252]. Indeed, raised levels of IL-6 in ascites and serum from ovarian cancer patients correlate with cisplatin and paclitaxel resistance and poor disease prognosis [259], whereas blockade of STAT3 expression in ovarian cancer cells increases their sensitivity to paclitaxel [254]. The expression of IL- 6 and its downstream signaling proteins is upregulated in ovarian clear cell adenocarcinoma (OCCA) and EOC $[7,260]$.

A recent study has shown unequivocally that siltuximab (a monoclonal anti-IL-6 antibody) significantly reduced ovarian cancer expression of STAT3 downstream proteins such as Mcl-1, Bcl-X(L), and survivin, implying proapoptotic effects. In the same study, metastatic and drug-resistant recurrent ovarian tumors expressed significantly higher IL-6 levels than primary ovarian cancer tissue [261]. By the same token, administration of sunitinib, a potent multikinase (VEGFR, PDGFR, and KIT) inhibitor, to two OCCA patients with progressive disease and refractory to conventional chemotherapy resulted in markedly lower levels of CA125 and notable reduction in tumor mass [7]. The possible mechanistic correlation for the favorable responses seen in these patients had been advanced as inhibition by sunitinib of IL-6, STAT3, and hypoxia-induced factor (HIF). Thus, the upregulation of the IL6-STAT3-HIF pathway in OCCA may be exploited as a biomarker to clinically differentiate 
OCCA from other ovarian tumor types [7], and inhibition of the IL-6-STAT3 signaling autocrine pathway may offer yet another molecular targeting strategy in the management of cisplatin- and paclitaxel-resistant ovarian cancers [259, 262]. The observation that crosstalk between the EGFR and IL-6R signaling through JAK/STAT3 mediates EMT in ovarian cancers further adds to the number of exploitable opportunities that are emerging to target the molecular intricacies that underscore the aggressive phenotype of ovarian cancer and its recurrence in patients [258, 263, 264]. Generic strategies to target the IL-6R-JAK-STAT3 signaling axis include receptor-ligand antagonists or antibodies, tyrosine or serine kinase inhibitors, transcription factor decoy (siRNA), physiological protein modulators of STAT3 activation, disrupters of STAT dimerization, inhibitors of STAT3 nuclear translocation, and target gene transcription [257].

Nuclear factor kappaB (NF- $\kappa \mathrm{B})$ is a highly inducible transcription factor which regulates several inflammatory response and cancer signaling pathways [252, 265, 266]. NF$\kappa \mathrm{B}$ is constitutively expressed in the majority of tumors, including ovarian cancer $[80,256,257,266]$. Many cytokineinduced signaling pathways that control inflammation and cancer converge on NF- $\kappa \mathrm{B}$ and STAT3 [252]. The mammalian NF- $\kappa$ B family comprises five members, namely, RelA (p65), RelB, cRel (Rel), NF- $\kappa B 1$ (p50 and its precursor p105), and NF- $\kappa B 2$ (p52 and its precursor p100) which form homo- and heterodimers whose activities are regulated by two key NF- $\kappa \mathrm{B}$ activation pathways. In the first (classical or canonical) pathway, RelA:p50 dimers are sequestered in an inactive conformation in the cytoplasm through interactions with inhibitory proteins, I- $\kappa \mathrm{B}$. Upon binding of ligands such as TNF- $\alpha$ or IL-1, viruses, genotoxic agents, and exposure to ionizing radiation, the $\mathrm{I}-\kappa \mathrm{B}$ molecules become phosphorylated at specific serine residues by the I$\kappa \mathrm{B}$ kinase complex (IKK, made up of two catalytic subunits, $\mathrm{IKK} \alpha$ and IKK $\beta$, and a regulatory subunit, NEMO/IKK $\gamma$ ) which results in their ubiquitylation and proteasomal degradation. The liberated RelA:p50 dimers translocate to the nucleus to activate transcription of several target genes that regulate innate immunity and inflammation. In the second (alternative or non-canonical) pathway which is stimulated almost exclusively by members of the TNF superfamily, an upstream NF- $\kappa$ B-inducing kinase (NIK) activates IKK $\alpha$, causing phosphorylation and proteasomal processing of p100, the principal RelB inhibitor, followed by RelB:p52 and RelB:p50 nuclear translocation and binding to genes responsible for regulating development, organization, and function of secondary lymphoid organs, B-cell maturation, and survival. Even though many genes are regulated by STAT3 and NF- $\kappa$ B, these two master regulators both favor the transcriptional activation of protumorigenic and antiapoptotic genes such as $B c l-x L, B c l-2$, and $c-I A P 2$, while $A 1$ and $c$-FLIP genes are predominantly NF- $\kappa \mathrm{B}$-dependent and $\mathrm{Mcl}$ 1 and survivin genes are STAT3-dependent [252, 256, 265, 266]. NF- $\kappa \mathrm{B}$ (RelA/p65) is overexpressed in advanced-stage metastatic serous ovarian carcinoma, and its localization to the nucleus is associated with poor PFS [267]. Using specimens from patients with IKK $\beta$-positive ovarian tumors and ovarian cancer cell lines, a recent study showed that activation of the NF- $\kappa$ B pathway by downregulating IKK $\beta$ activity with highly specific kinase inhibitors or through short hairpin RNA (shRNA), depletion of IKK $\beta$ correlated not only with a number of cellular expressions associated with the invasive phenotype of this cancer, but also with poor OS [80]. These findings are in agreement with the notion that constituent expression of NF- $\kappa \mathrm{B}$ in OCSCs, which may be the trigger of chemoresistance and disease recurrence, can be targeted by inactivation of NF- $\kappa$ B signaling $[25,247]$.

Although IL-6 signaling has been studied extensively in ovarian cancers, several reports have indicated the involvement of many other interleukins in the development of this neoplasm [248, 252]. These will not be considered further in this review, except to mention that IL-8 has previously been identified to have autocrine growth factor, tumorigenic and angiogenic effects in human ovarian cancer [268-273], but conflicting reports have also appeared [274]. Particularly noteworthy is the fact that activation of G-proteincoupled receptor protease-activated receptor-1 (PAR1) by matrix metalloproteinase (MMP1) is a principal promoter of angiogenesis and metastasis in peritoneal mouse models of ovarian cancer. In ovarian carcinoma cells, activated MMP1-PAR1 induces the release of angiogenic factors such as interleukin-8 (IL-8) and growth-regulated oncogenealpha (GRO- $\alpha$ ) which, through paracrine signaling, act on endothelial CXCR1/2 to effect endothelial cell proliferation, tube formation, and migration [110]. This pathway may be targeted to identify novel ovarian cancer therapies.

3.6. PI3K/AKT/mTOR Cell Signaling Pathway. The mammalian target of rapamycin (mTOR) is a central intracellular kinase that coordinates mitogenic, angiogenic, antiapoptotic, and survival pathways in cancers through crosstalk with VEGF, HIF-1, and the EGFR/ErbB family of RTKs [202]. PI3K/Akt/mTOR signaling thus confers a selective survival advantage on tumor cells [397]. Activators of this pathway include defective tumor suppressor PTEN, upregulation or mutation of PI3K and AKT, and ligand binding to growth factor receptors. Mutation or amplification of PI3K or Akt triggers mTOR phosphorylation and increased ovarian tumor cell survival [398]. A recent study has shown that $\mathrm{PI} 3 \mathrm{~K} / \mathrm{AKT} / \mathrm{mTOR}$ signaling is involved in EOC development and resistance to cisplatin, since downregulation of AKT with triciribine or shRNA transfection of ovarian cancer cells decreased their resistance to cisplatin via $\mathrm{mTOR} /$ survivin signaling [92]. In advanced-stage ovarian cancer, the mTOR pathway is upregulated, and hence its blockade will enhance ovarian cancer cell sensitivity to antitumor drugs [204]. In patients with serous ovarian carcinoma undergoing cisplatin-taxane-based therapy, activation of VEGFR2/AKT/mTOR pathway was significantly correlated with raised ascites levels and decreased OS [205]. mTOR has been implicated in the resistance of various cancers to EGFR inhibitors [202] and mTOR pathway activation is a poor prognosticator of EOC [84]. Furthermore, treatment of highly metastatic ovarian tumor cells with 
TABLE 1: Candidate biomarker profiles and the molecular basis for their targeting in ovarian cancers.

\begin{tabular}{|c|c|c|}
\hline \multicolumn{2}{|c|}{ Biomarker ${ }^{\dagger}$ Molecular basis for biomarker targeting in ovarian cancer } & \multirow{2}{*}{$\begin{array}{l}\text { References } \\
{[14,16,33} \\
34,59,275]\end{array}$} \\
\hline $\mathrm{M}-\mathrm{CSF}$ & $\begin{array}{l}\text { Hematopoietic cytokine that stimulates differentiation, activation, and proliferation of monocyte and } \\
\text { macrophages; can also act as an autocrine or paracrine growth factor for some epithelial cancers; promotes } \\
\text { vasculogenesis; modulates CSCs, and can thus be targeted in OCSCs to induce immune-mediated tumor cell } \\
\text { lysis; a phase II trial with GM-CSF and recombinant interferon gamma } 1 \mathrm{~b} \text { (rIFN- } \gamma 1 \mathrm{~b} \text { ) in women with } \\
\text { recurrent, platinum-sensitive ovarian, fallopian tube, and primary peritoneal cancer produced reasonable OS. }\end{array}$ & \\
\hline HNF-1 $\beta$ & $\begin{array}{l}\text { Overexpressed in ovarian clear cell adenocarcinoma (OCCC); reduction of HNF-1 } \beta \text { expression by RNA } \\
\text { interference induces apoptotic cell death in ovarian OCCC cells; HNF-1 } \beta \text { is hypomethylated in OCCC and can } \\
\text { thus be targeted in ovarian cancers. }\end{array}$ & {$[27$} \\
\hline HE4 & $\begin{array}{l}\text { A glycoprotein highly expressed in ovarian cancers that might have a role in ovarian carcinogenesis; HE4 } \\
\text { expression is highest in endometrioid and serous ovarian cancer }\end{array}$ & $\begin{array}{l}{[214,281,} \\
282]\end{array}$ \\
\hline OPN & $\begin{array}{l}\text { A glycophosphoprotein cytokine secreted by activated T-lymphocytes, macrophages, and leukocytes at the } \\
\text { inflammation site; higher levels occur in patients with ovarian cancer versus normal control; correlates } \\
\text { significantly with tumor response to surgery, chemotherapy, and disease recurrence; implicated in } \\
\text { tumorigenesis, tumor invasion, metastasis, and poor prognosis; binding of OPN as an ECM component to } \\
\text { integrin and CD } 44 \text { receptors in the tumor microenvioronment regulates signaling cascades associated with } \\
\text { adhesion, migration, invasion, chemotaxis, and cell survival; alternative splicing of OPN leads to } 3 \text { isoforms, } \\
\text { OPNa, OPNb, and OPNc; the latter possess ovarian protumorigenic properties mediated by PI3K/Akt signaling } \\
\text { pathway which serves as a critical cancer molecular target. }\end{array}$ & $\begin{array}{l}{[14,111,283-} \\
285]\end{array}$ \\
\hline
\end{tabular}
pathway which serves as a critical cancer molecular target.

Binding of MUC16 to MES, a GPI-anchored glycoprotein, is thought to facilitate cell adhesion and peritoneal

metastasis of ovarian tumors; this function can be exploited as a molecular targeting strategy, for example,

MES anti-MES antibodies, to limit the metastatic spread of the tumor; MES is an attractive candidate for adenoviruses-mediated gene therapy of ovarian cancers; diffuse mesothelin expression is associated with adenoviruses-mediated gene therapy of ovarian cancers; diffuse mesothelin
prolonged survival in patients with high-grade ovarian serous carcinoma.

Glycoprotein synthesized in the liver, but also present in ascites and serum of ovarian cancer patients;

HP- $\alpha$ proteomic profiling identified HP- $\alpha$ as a potential biomarker with high specificity for ovarian cancer; high levels of this acute phase protein correlate with poor prognosis, but attenuate with chemotherapy—-this mechanism should be explored further.

This glycosylated protease suppresses ovarian tumor cell invasion and metastasis by downregulating PI3K and $\mathrm{Ca}^{2+}$-dependent TGF- $\beta$ signaling pathways; plasma BIK is a strong prognostic indicator of ovarian cancer; a combination of BIK and paclitaxel significantly reduced tumor burden and ascites in a mouse model of ovarian cancer; BIK overexpression has been shown to suppress TNF-induced apoptosis in ovarian cancer cells; BIK

BIK also downregulates UPA/R and HBP gene expression in ovarian cancer cells; other target genes of BIK include transcriptional regulators, oncogenes/tumor suppressor genes, signaling molecules, growth/cell cycle, invasion/metastasis, cytokines, apoptosis, ion channels, and ECM proteins; the evidence cited here underlines the applicability of BIK in therapeutic strategies targeting the inhibition of peritoneal invasion and dissemination of ovarian cancer.

This protein is an alternative folate transporter which may confer an increased DNA synthesis and growth advantage on tumor cells; ovarian cancer patients have elevated blood levels of this protein, identified as a diagnostic marker and molecular target in high-grade, high-stage serous tumors; the status of FR $\alpha$ apparently does not change in response to chemotherapy and has no effect on overall patient survival; however, farletuzumab, a humanized monoclonal antibody against FR $\alpha$, demonstrated anticancer efficacy in patients with platinum-refractory/resistant EOC; FR $\alpha$ expression is preserved on metastatic foci and recurrent tumors, suggesting that novel folate-targeted therapies may have therapeutic potential for the majority of women with

FR $\alpha \quad$ does not change in response to chemotherapy
farletuzumab, a humanized monoclonal antib
with platinum-refractory/resistant EOC; FR $\alpha$
suggesting that novel folate-targeted therapies
newly diagnosed or recurrent ovarian cancer. This is a highly sensitive biomarker used in the screening of prostate, lung, colorectal, and ovarian (PLCO)

TTR cancers; was found to be downregulated in grade 3 ovarian tumors; and has been validated for its high specificity and sensitivity in early-stage ovarian cancer; further research on TTR is needed to explore its molecular targeting possibilities.

The expression of this protein is reportedly upregulated in ovarian cancer patients and it is used mainly to

$\mathrm{I} \alpha \mathrm{I} \quad$ complement MUC16/CA125 in the screening for EOC; however, proteomic analysis showed its levels to be significantly reduced in the urine of patients with ovarian carcinoma. Is one of a panel of plasma biomarkers used for the identification of women with ovarian cancer and to significantly increase diagnostic performance compared to MUC16/CA125 used singly; raised serum levels of

CRP CRP is associated with high levels of Il-6 and haptoglobin, considered as adverse prognostic factors in ovarian cancer; CRP are also a marker of high-grade inflammation in advanced-stage ovarian cancer and anemia in EOC (i.e., CRP correlates negatively with hemoglobin levels); high levels of prediagnostic CRP may indicate an 307] inflammation stage that precedes ovarian cancer development and might denote increased risk. 
TABle 1: Continued.

Biomarker ${ }^{\dagger}$ Molecular basis for biomarker targeting in ovarian cancer References

This channel-activating serine protease is overexpressed in EOC; it is localized to the apical surface of normal

PRSS epithelial cells and suppresses cancer cell invasion in vitro; in various cancer cell lines, PRSS downregulates EGFR signaling by cleaving its extracellular domain and hence interferes with cell proliferation and tumor

$[14,71,72$, expansion; this property should be investigated as a molecular target.

Large family of integral membrane proteins essential for tight junction formation and function; CLDN3 and CLDN4 expression levels are upregulated in EOCs of all subtypes and correlate with MMP-2 activity; CLDNs may promote ovarian cancer invasion and metastasis; CLDN upregulation in ovarian carcinoma effusions is associated with poor survival; cells that overexpress CLDN4 exhibit low DNA methylation and high histone H3

CLDNs acetylation of the critical CLDN4 promoter region, while the converse is true for cells that do not overexpress it; [317-326] CLDN4-expressing EOC cells secrete proangiogenic factors (e.g., IL-8) and downregulate genes of the angiostatic IFN pathway; CLDN5 overexpression is associated with aggressive behavior in serous ovarian adenocarcinoma; CLDNs are, therefore, suitable biomarkers for different types of ovarian cancer and promising molecular targets for ovarian cancer therapy.

Is the protein component of HDL; the APOA1 gene is upregulated in chemoresistant EOC and has an established role in tumorigenesis; algorithmic proteomic profiling of postdiagnostic/pretreatment sera of

APOA1 women with ovarian cancer revealed that the ApoA1 and TTR combination yield high specifity, but low sensitivity as tumor markers; further investigations into the mechanistic roles of APOA1 in ovarian tumorigenesis are crucial for its consideration as a molecular target in ovarian cancer.

Generated by the action of the enzyme, lysophospholipase; LPA is the ligand for GPCRs (LPAR2 and LPAR3) which are upregulated during ovarian tumorigenesis; LPA is a bioactive lipid central to the initiation and progression of ovarian cancer; LPA is preferable to MUC16/CA125 as a biomarker for the diagnosis, but not the prognosis of EOC; in human EOC tissues obtained from patients, LPA-induced POSTN (an ECM constituent, see the following) expression in cancer-associated stromal fibroblasts correlates with poor survival and recurrence; remarkably, LPA also regulates IL-6 expression and STAT3 phosphorylation via the $\mathrm{Gi} / \mathrm{PI} 3 \mathrm{~K}-\mathrm{Akt} / \mathrm{NF}-\kappa \mathrm{B}$ pathway in ovarian cancer cells; LPA enhances growth and invasion of ovarian cancer cells and tumor angiogenesis; active RTK and EGFR signaling is required for LPA-mediated Gi-dependent cellular responses in ovarian cancer cells; LPA antibodies, LPA antagonists, and LPAR gene silencing may thus be useful molecular targeting strategies in ovarian cancer.

POSTN is an ECM protein which normally functions as a homophilic adhesion molecule in bone formation; 5 isoforms have so far been identified; targeted comparative glycotranscriptome analyses of ovarian cancer and normal ovarian tissues have shown that POSTN and thrombospondin may be useful biomarkers for specific tumor-specific glycan changes in benign ovarian adenomas, borderline ovarian adenocarcinomas, as well as malignant ovarian adenocarcinomas; POSTN binds to numerous cell-surface receptors, predominantly integrins, and signals effectively via the PI3K/Akt and other pathways to promote cancer cell survival, EMT, invasion, metastasis, and angiogenesis; ovarian cancer cells actively secrete the protein; interaction of the ligand, POSTN, with integrins facilitates ovarian cancer cell motility; antibodies directed against POSTN have been shown to inhibit growth and metastasis of subcutaneous and ovarian tumors derived from a POSTN-expressing ovarian cancer cell line; thus, POSTN represents a novel molecular-targeted therapy for ovarian cancer.

Largest family of flanking proteases in the human genome, comprising at least 15 members; KLKs are secreted serine proteases that stimulate or inhibit tumor progression; KLK5-11 levels are typically elevated in sera of ovarian cancer patients and regarded as predictors of poor disease prognosis; aberrant $K L K$ gene expressions in different types of ovarian cancers may complicate generalizations; for example, high tumor KLK6 protein expression correlates with inferior patient outcome in ovarian cancer, while raised KLK8 is an independent marker of favorable prognosis in ovarian cancer, whereas KLK5 levels are low in serum of patients with benign ovarian tumors; elevated KLK5 antigen in serum and ascitic fluid of ovarian cancer patients is a prognostic

KLK factor for PFS; KLK5-specific antibodies have been detected in patients with benign masses, borderline tumors, [60, 346-365] and ovarian carcinomas compared with healthy controls; the presence of KLK5 antibodies suggests that KLK5 might represent a possible target for immune-based therapies; KLK6 exemplifies the altered glycosylation hallmark of ovarian cancer; KLK7 is associated with negative characteristics of ovarian cancer, but is not considered an independent prognosticator for the disease; a combined panel of KLK6, KLK13, and MUC16/CA125 affords improved sensitivity in the detection of early stage ovarian cancer than MUC16/CA125 alone; KLKs have recently been shown to be subject to posttranscriptional control by multiple miRNAs which can be exploited in the differential diagnosis of ovarian cancer and as a molecular targeting opportunity.

This is a mucinous metastasis-inducing protein detectable in the plasma of ovarian cancer patients; elevated AGR2 levels in ovarian cancer patients are associated with disease stages II and III in both serous and nonserous tumors; AGR2 is thought to promote cell proliferation and migration; it is currently being validated for its diagnostic and prognostic significance in ovarian cancers. 
TABle 1: Continued.

\begin{tabular}{|c|c|c|}
\hline Biomarke & ${ }^{\dagger}$ Molecular basis for biomarker targeting in ovarian cancer & References \\
\hline HDACs & 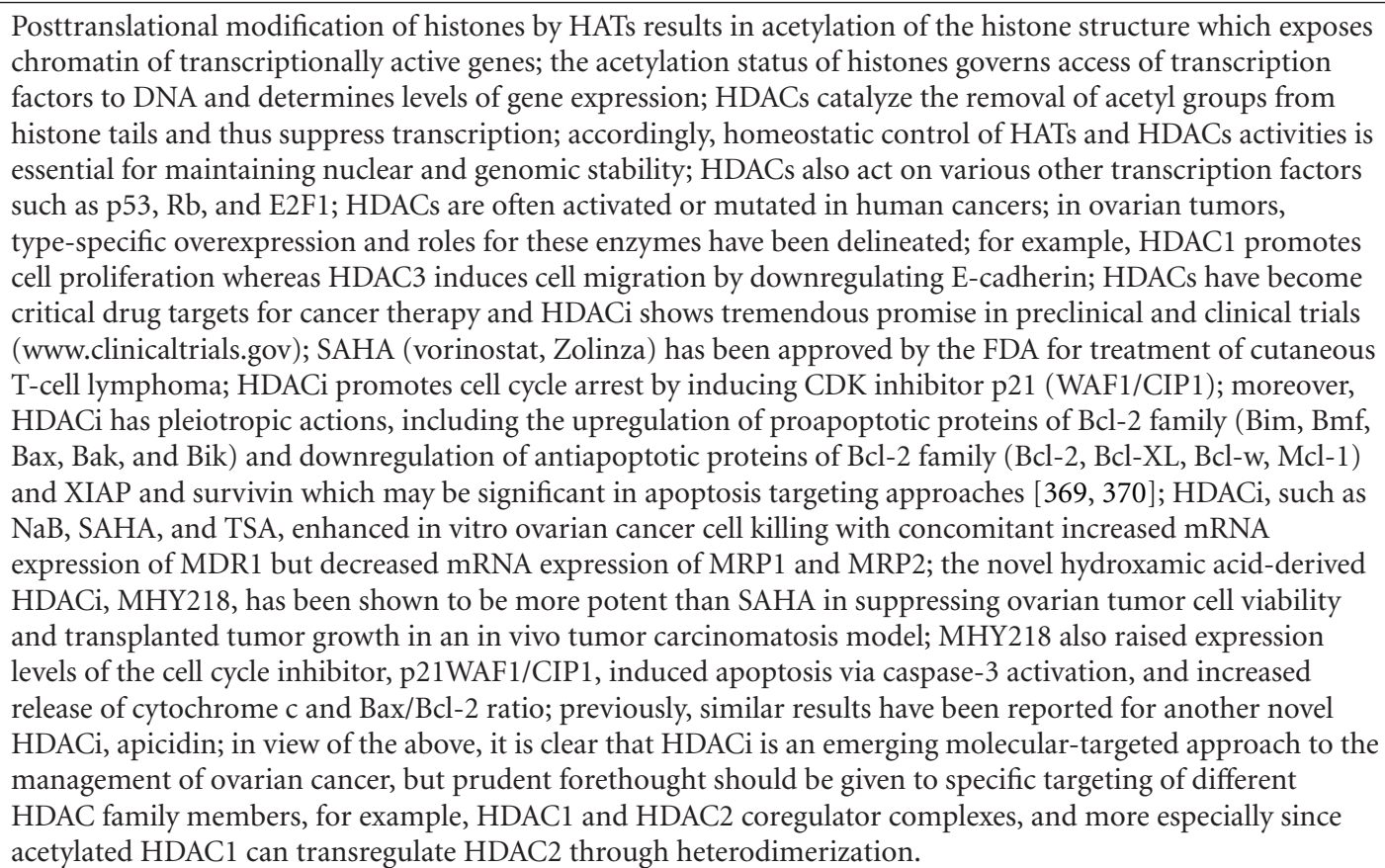 & $\begin{array}{l} \\
\\
{[327,371-} \\
386]\end{array}$ \\
\hline
\end{tabular}

MicroRNAs belong to a family of endogenous, small RNAs ( $\sim 22$ nucleotides); these noncoding, yet functional RNAs are key regulators of coding genes in the human genome; microarray analysis of altered expression of miRNAs provides useful information on the ontogeny and differentiation status of various cancers; genomic and epigenetic modifications are known to deregulate miRNA expression in human EOC; a recent study showed that several miRNAs (let-7e, miR-30c, miR-125b, miR-130a, and miR-335) were differentially expressed and upregulated in paclitaxel- and cisplatin-resistant ovarian cancer cell lines and concluded that the development of drug resistance in ovarian cancer may be linked to distinct miRNA fingerprints that could be used as biomarkers to monitor disease prognosis; deregulation of miRNA-27a may correlate with the development of drug resistance by regulating the expression of MDR1/P-glycoprotein targeting HIPK2 in ovarian cancer cells; deregulation of miR-214, miR-199a, miR-200a, and miR-100 has also been demonstrated

miRNAs $^{\ddagger}$ to occur in ovarian cancers; miR-214 promotes cell survival and cisplatin resistance by targeting the PTEN/Akt pathway; lack of miRNA-31 expression has been linked to a defective p53 pathway in serous ovarian cancer patients, raising hopes that treatment with miRNA-31 may offer an efficacious strategy in the management of such patients; miRNA-125a is a negative regulator of EMT since it induces reversion of highly invasive ovarian cancer cells from a mesenchymal to an epithelial histotype; this finding represents a landmark in ovarian cancer therapeutics since overexpression of EGFR is coupled to EMT in ovarian cancer cells which correlates with poor prognosis; the expression of miRNA-200 family members in ovarian tumors obtained from patients correlated with raised levels of $\beta$-tubulin and poor PFS to paclitaxel-based treatment; some miRNAs have been identified as putative tumor suppressor genes in ovarian tumors; thus specific miRNA signatures may be exploited as biomarkers for progression and recurrence of advanced stage ovarian carcinoma patients, and as molecular targets in ovarian cancer.

\footnotetext{
${ }^{\dagger}$ Granulocyte/macrophage-colony stimulating factor (G/M-CSF); hepatocyte nuclear factor-1 $\beta$ (HNF-1 $\beta$ ); human epididymis protein 4 (HE4); osteopontin $(\mathrm{OPN})$; mesothelin (MES); haptoglobin- $\alpha$ (HP- $\alpha$ ); Bikunin (BIK); phosphoinositide-3-kinase (PI3K); transforming growth factor-beta (TGF- $\beta$ ); tumor necrosis factor (TNF); urokinase plasminogen activator and its receptor (uPA/R); hyaluronan-binding protein (HBP); extracellular matrix (ECM); folate receptor alpha (FR $\alpha$ ); transthyretin (TTR); inter- $\alpha$-trypsin inhibitor (I $\alpha$ I); C-reactive protein (CRP); prostasin (PRSS); claudin/s (CLDN/s); matrix metalloproteinase-2 (MMP-2); interferon (IFN); apoliprotein A1 (APOA1); high-density lipoprotein (HDL); lysophosphatidic acid (LPA); G-protein coupled receptors (GPCRs); receptor tyrosine kinase (RTK); periostin (POSTN, also called osteoblast specific factor 2, OSF2); kallikrein/s (KLKs); human anterior gradient 2 (AGR2); histone acetyltransferase/s (HAT/s); histone deacetylase/s (HDAC/s); histone deacetylase inhibitors (HDACi); suberoylanilide hydroxamic acid (SAHA); sodium butyrate (NaB); trichostatin A (TSA); multidrug-resistant protein (MDR1, P-glycoprotein); multidrug resistance-associated proteins 1 and 2 (MRP1/2); microRNAs (miRNAs); extracellular matrix (ECM); homeodomain-interacting protein kinase-2 (HIPK2); glycosylphosphatidylinositol (GPI). All these biomarkers are used in various multimodal combinations in the screening/detection of ovarian cancer in high risk women. ${ }^{\ddagger}$ For more information, see (http://www.sanger.ac.uk/Software/Rfam/mirna/).
} 
bikunin (BIK) or upregulating BIK gene expression in these cells significantly attenuated $\mathrm{PI} 3 \mathrm{~K} / \mathrm{p} 85$ gene expression, and decreased their urokinase-type plasminogen activator- (uPA) dependent invasive potential in nude mice [292]. Therefore, the molecular targeting of multiple signaling pathways such as EGFR, VEGFR, HIF-1, and PI3K/PTEN/AKT/mTOR may improve responses in recurrent and resistant ovarian cancers $[4,83,92,203,205,399-403]$.

3.7. ATP-Binding Cassette ( $A B C$ ) Drug Transporters. Despite the encouraging response rates of ovarian cancer patients to a combination regimen of carboplatin and paclitaxel, most will experience recurrence and/or relapse. Disease recurrence is mostly associated with the development of multidrug resistance (MDR) which is mediated by the overexpression of tumor ATP-binding cassette $(\mathrm{ABC})$ drug transporters. In ovarian cancer cells, the $A B C B 1$ (MDR1) gene encodes P-glycoprotein, which targets to the luminal surface and actively effluxes a wide array of anticancer drugs, including carboplatin and paclitaxel [404-406]. P-glycoprotein expression has been shown to be a predictor of unfavorable response (recurrence) and poor survival in uniformly treated and followed cohorts of advanced ovarian cancer patients [407-409]. Reversal of MDR in ovarian cancer cell lines is possible with siRNA knockout of $A B C B 1$ (MDR1) and $A B C B 4$ (MDR3) genes [410, 411], combination drug treatments [412, 413], chitosan/pshRNA plasmid nanoparticle targeting of MDR1 genes [414], and perturbation of Pglycoprotein N-glycosylation [415]. The prognostic value of $A B C B 1$ gene polymorphisms in ovarian cancer patients is conflicting, for example, whereas a recent study found that ABCB1 G2677T/A and ABCB1 C3435T gene polymorphisms did not correlate with survival and prognosis in Caucasian women with ovarian cancer [416, 417], another study found such a relationship [418]. Analogous earlier reports concluded that although MDR1 expression profiles may be closely related to histologic subtype of ovarian cancer, they were not accurate predictors of survival $[419,420]$. Remarkably, elevated expression of MDR-1 in tumor tissue sampled after first cytoreductive surgery was associated with a higher risk of brain metastases in women with epithelial ovarian, fallopian tube, or peritoneal cancer [421]. Noteworthy also is the observation that chemoresistance induced by IL-6R signaling correlated with enhanced expression of MDR genes (MDR1 and GSTpi), antiapoptotic proteins (Bcl2, Bcl-xL, and XIAP), and upregulation of Ras/MEK/ERK and PI3K/Akt signaling [259]. Undoubtedly, more research is required to unravel the complex expression of the MDR phenotype in ovarian cancers.

\section{Candidate Ovarian Cancer Biomarkers as Molecular Targets}

Candidate biomarker profiles and the molecular basis for their targeting in ovarian cancers are summarized in Table 1.

\section{Conclusion}

This aim of this review was to present a broad overview of how improved diagnostic and prognostic specificity and sensitivity of tumor biomarkers and signaling molecules can be translated into more efficacious molecularly targeted therapies that will prevent resistance, recurrence, and relapse in ovarian cancer patients. The different types of ovarian cancers variously express the major hallmarks of cancer such as genomic instability, gain of oncogenes, loss of tumor suppressors, immeasurable self-renewal potential, epithelialto-mesenchymal transition, and reversed mutational capacities, autocrine signaling and self-sufficiency in growth factor requirements, host immune co-option, escape from immune surveillance and natural killer cell mediated oncolysis, apoptosis evasion, increased DNA repair mechanisms, sustained angiogenesis, invasion, and metastatic spread. The rapid increase in our understanding of the molecular processes that regulate cancer signatures in general has raised an equally strong desire to eradicate ovarian cancer before resistance, recurrence, and relapse can set in and claim more lives. It is becoming increasingly evident that traditional approaches to ovarian cancer management such as surgical debulking and carboplatin-paclitaxel chemotherapy will have to be complemented with molecularly targeted and personalized treatment approaches to impact positively on PFS and OS rates. The molecular therapeutic targeting paradigm and the concept of synthetic lethality as exemplified by BRCA1/2 mutations and PARP inhibition offer profound opportunities for ovarian cancer drug development and discovery. The targeting of multiple signaling pathways such as VEGFR, EGFR, IL-6R-JAK-STAT3/NF- $\kappa$ B, $\mathrm{PI} 3 \mathrm{~K} / \mathrm{AKT} / \mathrm{mTOR}$, and $\mathrm{ABC}$ drug transporters in ovarian cancer may be an auspicious start to favourable PFS and OS outcomes. The Wnt $/ \beta$-catenin signaling pathway should not be overlooked since it has recently been implicated in regulating the immunoreactivity and chemosensitivity to anticancer drugs in ovarian cancer cells, which may be a useful prognostic indicator in patients with ovarian cancer [422]. The interaction between MUC16 and MES should be seen as an opportunity to block intra- and extraperitoneal metastasis of highly aggressive ovarian cancers and to develop effective antibodies and vaccines against this type of cancer which is a major contributor to the high mortality rate among women worldwide. Finally, candidate or emerging biomarkers, especially HDACi and miRNAs, and their molecular interactions with cancer signaling pathways should be translated into cross-spectrum and individualized therapies for the different histological subtypes of ovarian cancer.

\section{Conflict of Interests}

The author declared that he has no conflict of interest.

\section{Acknowledgments}

This work was supported by grants from the University of the Western Cape and the Ackerman Family Educational Trust. 


\section{References}

[1] S. Banerjee and M. Gore, "The future of targeted therapies in ovarian cancer," Oncologist, vol. 14, no. 7, pp. 706-716, 2009.

[2] R. C. Bast, B. Hennessy, and G. B. Mills, "The biology of ovarian cancer: new opportunities for translation," Nature Reviews Cancer, vol. 9, no. 6, pp. 415-428, 2009.

[3] V. Guarneri, F. Piacentini, E. Barbieri, and P. F. Conte, "Achievements and unmet needs in the management of advanced ovarian cancer," Gynecologic Oncology, vol. 117, no. 2, pp. 152-158, 2010.

[4] H. Itamochi, "Targeted therapies in epithelial ovarian cancer: molecular mechanisms of action," World Journal of Biological Chemistry, vol. 1, no. 7, pp. 209-220, 2010.

[5] A. Jemal, F. Bray, M. M. Center, J. Ferlay, E. Ward, and D. Forman, "Global cancer statistics," CA Cancer Journal for Clinicians, vol. 61, no. 2, pp. 69-90, 2011.

[6] R. Siegel, E. Ward, O. Brawley, and A. Jemal, "Cancer statistics, 2011: the impact of eliminating socioeconomic and racial disparities on premature cancer deaths," CA Cancer Journal for Clinicians, vol. 61, no. 4, pp. 212-236, 2011.

[7] M. S. Anglesio, J. George, H. Kulbe et al., "IL6-STAT3HIF signaling and therapeutic response to the angiogenesis inhibitor sunitinib in ovarian clear cell cancer," Clinical Cancer Research, vol. 17, no. 8, pp. 2538-2548, 2011.

[8] C. M. Annunziata and E. C. Kohn, "Is there a genomic basis for primary chemoresistance in ovarian cancer?" Gynecologic Oncology, vol. 90, no. 1, pp. 1-2, 2003.

[9] V. Barrès, V. Ouellet, J. Lafontaine, P. N. Tonin, D. M. Provencher, and A. M. Mes-Masson, "An essential role for Ran GTPase in epithelial ovarian cancer cell survival," Molecular Cancer, vol. 9, article no. 272, 2010.

[10] A. L. Creekmore, W. T. Silkworth, D. Cimini, R. V. Jensen, P. C. Roberts, and E. M. Schmelz, "Changes in gene expression and cellular architecture in an ovarian cancer progression model," PLoS One, vol. 6, no. 3, Article ID e17676, 2011.

[11] C. Gómez-Raposo, M. Mendiola, J. Barriuso, D. Hardisson, and A. Redondo, "Molecular characterization of ovarian cancer by gene-expression profiling," Gynecologic Oncology, vol. 118, no. 1, pp. 88-92, 2010.

[12] B. T. Hennessy, R. L. Coleman, and M. Markman, "Ovarian cancer," The Lancet, vol. 374, no. 9698, pp. 1371-1382, 2009.

[13] S. A. Hubbard and C. E. Gargett, "A cancer stem cell origin for human endometrial carcinoma?" Reproduction, vol. 140, no. 1, pp. 23-32, 2010.

[14] N. Husseinzadeh, "Status of tumor markers in epithelial ovarian cancer has there been any progress? A review," Gynecologic Oncology, vol. 120, no. 1, pp. 152-157, 2011.

[15] D. Jelovac and D. K. Armstrong, "Recent progress in the diagnosis and treatment of ovarian cancer," CA Cancer Journal for Clinicians, vol. 61, no. 3, pp. 183-203, 2011.

[16] T. Kaur, R. A. Slavcev, and S. D. Wettig, "Addressing the challenge: current and future directions in ovarian cancer therapy," Current Gene Therapy, vol. 9, no. 6, pp. 434-458, 2009.

[17] M. J. Kwon and Y. K. Shin, "Epigenetic regulation of cancerassociated genes in ovarian cancer," International Journal of Molecular Sciences, vol. 12, no. 2, pp. 983-1008, 2011.

[18] E. J. Nam and Y. T. Kim, "Alteration of cell-cycle regulation in epithelial ovarian cancer," International Journal of Gynecological Cancer, vol. 18, no. 6, pp. 1169-1182, 2008.

[19] R. Strauss, Z. Y. Li, Y. Liu et al., "Analysis of epithelial and mesenchymal markers in ovarian cancer reveals phenotypic heterogeneity and plasticity," PLoS One, vol. 6, no. 1, Article ID e16186, 2011.

[20] J. Chen, L. Wang, L. V. Matyunina, C. G. Hill, and J. F. McDonald, "Overexpression of miR-429 induces mesenchymal-to-epithelial transition (MET) in metastatic ovarian cancer cells," Gynecologic Oncology, vol. 121, no. 1, pp. 200205, 2011.

[21] A. Halon, V. Materna, M. Drag-Zalesinska et al., "Estrogen receptor alpha expression in ovarian cancer predicts longer overall survival," Pathology and Oncology Research, vol. 17, no. 3, pp. 1-8, 2011.

[22] B. G. Hollier, K. Evans, and S. A. Mani, "The epithelial-tomesenchymal transition and cancer stem cells: a coalition against cancer therapies," Journal of Mammary Gland Biology and Neoplasia, vol. 14, no. 1, pp. 29-43, 2009.

[23] K. Pliarchopoulou and D. Pectasides, "Epithelial ovarian cancer: focus on targeted therapy," Critical Reviews in Oncology/Hematology, vol. 79, no. 1, pp. 17-23, 2010.

[24] D. Vergara, B. Merlot, J. P. Lucot et al., "Epithelial-mesenchymal transition in ovarian cancer," Cancer Letters, vol. 291, no. 1, pp. 59-66, 2010.

[25] A. B. Alvero, R. Chen, H. H. Fu et al., "Molecular phenotyping of human ovarian cancer stem cells unravel the mechanisms for repair and chemo-resistance," Cell Cycle, vol. 8, no. 1, pp. 158-166, 2009.

[26] R. Lis, C. Touboul, P. Mirshahi et al., "Tumor associated mesenchymal stem cells protects ovarian cancer cells from hyperthermia through CXCL12," International Journal of Cancer, vol. 128, no. 3, pp. 715-725, 2011.

[27] S. Zhang, C. Balch, M. W. Chan et al., "Identification and characterization of ovarian cancer-initiating cells from primary human tumors," Cancer Research, vol. 68, no. 11, pp. 4311-4320, 2008.

[28] B. M. Boman and M. S. Wicha, "Cancer stem cells: a step toward the cure," Journal of Clinical Oncology, vol. 26, no. 17, pp. 2795-2799, 2008.

[29] L. Calorini and F. Bianchini, "Environmental control of invasiveness and metastatic dissemination of tumor cells: role of tumor cell-host cell interactions," Cell Communication and Signaling, vol. 8, p. 24, 2010.

[30] H. Du and H. S. Taylor, "Stem cells and reproduction," Current Opinion in Obstetrics and Gynecology, vol. 22, no. 3, pp. 235-241, 2010.

[31] M. Ganzinelli, P. Mariani, D. Cattaneo et al., "Expression of DNA repair genes in ovarian cancer samples: biological and clinical considerations," European Journal of Cancer, vol. 47, no. 7, pp. 1086-1094, 2011.

[32] P. C. Hermann, S. Bhaskar, M. Cioffi, and C. Heeschen, "Cancer stem cells in solid tumors," Seminars in Cancer Biology, vol. 20, no. 2, pp. 77-84, 2010.

[33] H. G. Liu, C. Chen, H. Yang, Y. F. Pan, and X. H. Zhang, "Cancer stem cell subsets and their relationships," Journal of Translational Medicine, vol. 9, p. 50, 2011.

[34] L. Moserle, M. Ghisi, A. Amadori, and S. Indraccolo, "Side population and cancer stem cells: therapeutic implications," Cancer Letters, vol. 288, no. 1, pp. 1-9, 2010.

[35] L. R. Rogers and M. Wicha, "Therapeutic approaches to target cancer stem cells," in Regulatory Networks in Stem Cells, V. K. Rajasekhar and M. C. Vemuri, Eds., pp. 545-560, Humana Press, New York, NY, USA, 2009.

[36] A. D. Santin, "Prospective identification and characterization of ovarian cancer stem cells: implications for the treatment 
of chemotherapy resistant/recurrent ovarian disease," Cell Cycle, vol. 8, no. 1, p. 3, 2009.

[37] H.-C. Wu, D.-K. Chang, and C.-T. Huang, "Targeted Therapy for Cancer," Journal of Cancer Molecules, vol. 2, no. 2, pp. 5766, 2006.

[38] B.-B. S. Zhou, H. Zhang, M. Damelin, K. G. Geles, J. C. Grindley, and P. B. Dirks, "Tumour-initiating cells: challenges and opportunities for anticancer drug discovery," Nature Reviews Drug Discovery, vol. 8, no. 10, pp. 806-823, 2009.

[39] R. C. Bast and G. B. Mills, "Personalizing therapy for ovarian cancer: BRCAness and beyond," Journal of Clinical Oncology, vol. 28, no. 22, pp. 3545-3548, 2010.

[40] R. Agarwal, C. Gourley, T. J. Perren et al., "First-line therapy for ovarian cancer with carboplatin followed by paclitaxelgemcitabine (SCOTROC5): a feasibility study and comparative analysis of the SCOTROC series," European Journal of Cancer, vol. 46, no. 11, pp. 2020-2026, 2010.

[41] K. Rowan, "Intraperitoneal therapy for ovarian cancer: why has it not become standard?" Journal of the National Cancer Institute, vol. 101, no. 11, pp. 775-777, 2009.

[42] G. D. Aletti, E. L. Eisenhauer, A. Santillan et al., "Identification of patient groups at highest risk from traditional approach to ovarian cancer treatment," Gynecologic Oncology, vol. 120, no. 1, pp. 23-28, 2011.

[43] C. Fotopoulou, R. Richter, I. E. Braicu et al., "Clinical outcome of tertiary surgical cytoreduction in patients with recurrent epithelial ovarian cancer," Annals of Surgical Oncology, vol. 18, no. 1, pp. 1-9, 2010.

[44] J. S. Frenel, C. Leux, L. Pouplin et al., "Oxaliplatin-based hyperthermic intraperitoneal chemotherapy in primary or recurrent epithelial ovarian cancer: a pilot study of 31 patients," Journal of Surgical Oncology, vol. 103, no. 1, pp. 10$16,2011$.

[45] R. Fruscio, A. Garbi, G. Parma et al., "Randomized phase III clinical trial evaluating weekly cisplatin for advanced epithelial ovarian cancer," Journal of the National Cancer Institute, vol. 103, no. 4, pp. 347-351, 2011.

[46] I. Ramirez, H. S. Chon, and S. M. Apte, "The role of surgery in the management of epithelial ovarian cancer," Cancer Control, vol. 18, no. 1, pp. 22-30, 2011.

[47] T. Foster, T. M. Brown, J. Chang, H. D. Menssen, M. B. Blieden, and T. J. Herzog, "A review of the current evidence for maintenance therapy in ovarian cancer," Gynecologic Oncology, vol. 115, no. 2, pp. 290-301, 2009.

[48] L. M. Hess, N. Rong, P. O. Monahan, P. Gupta, C. Thomaskutty, and D. Matei, "Continued chemotherapy after complete response to primary therapy among women with advanced ovarian cancer," Cancer, vol. 116, no. 22, pp. 52515260, 2010.

[49] S. B. Kaye, N. Colombo, B. J. Monk et al., "Trabectedin plus pegylated liposomal doxorubicin in relapsed ovarian cancer delays third-line chemotherapy and prolongs the platinumfree interval," Annals of Oncology, vol. 22, no. 1, pp. 49-58, 2011.

[50] C. A. Kunos, M. W. Sill, T. E. Buekers et al., "Low-dose abdominal radiation as a docetaxel chemosensitizer for recurrent epithelial ovarian cancer: a phase I study of the Gynecologic Oncology Group," Gynecologic Oncology, vol. 120, no. 2, pp. 224-228, 2010.

[51] D. M. O’Malley, D. L. Richardson, P. S. Rheaume et al., "Addition of bevacizumab to weekly paclitaxel significantly improves progression-free survival in heavily pretreated recurrent epithelial ovarian cancer," Gynecologic Oncology, vol. 121, no. 2, pp. 269-272, 2011.

[52] I. Rizvi, J. P. Celli, C. L. Evans et al., "Synergistic enhancement of carboplatin efficacy with photodynamic therapy in a threedimensional model for micrometastatic ovarian cancer," Cancer Research, vol. 70, no. 22, pp. 9319-9328, 2010.

[53] G. A. Sarosy, M. M. Hussain, M. V. Seiden et al., "Ten-year follow-up of a phase 2 study of dose-intense paclitaxel with cisplatin and cyclophosphamide as initial therapy for poorprognosis, advanced-stage epithelial ovarian cancer," Cancer, vol. 116, no. 6, pp. 1476-1484, 2010.

[54] J. Sehouli, D. Stengel, P. Harter et al., “Topotecan weekly versus conventional 5-day schedule in patients with platinumresistant ovarian cancer: a randomized multicenter phase II trial of the North-Eastern German Society of Gynecological Oncology Ovarian Cancer Study Group," Journal of Clinical Oncology, vol. 29, no. 2, pp. 242-248, 2011.

[55] P. M. Vencken, M. Kriege, D. Hoogwerf et al., "Chemosensitivity and outcome of BRCA1- and BRCA2-associated ovarian cancer patients after first-line chemotherapy compared with sporadic ovarian cancer patients," Annals of Oncology, vol. 22, no. 6, pp. 1346-1352, 2011.

[56] H. S. Chon and J. M. Lancaster, "Microarray-based gene expression studies in ovarian cancer," Cancer Control, vol. 18, no. 1, pp. 8-15, 2011.

[57] J. M. Cragun, "Screening for ovarian cancer," Cancer Control, vol. 18, no. 1, pp. 16-21, 2011.

[58] D. W. Cramer, R. C. Bast Jr., C. D. Berg et al., "Ovarian cancer biomarker performance in prostate, lung, colorectal, and ovarian cancer screening trial specimens," Cancer Prevention Research, vol. 4, no. 3, pp. 365-374, 2011.

[59] M. Donach, Y. Yu, G. Artioli et al., "Combined use of biomarkers for detection of ovarian cancer in high-risk women," Tumor Biology, vol. 31, no. 3, pp. 209-215, 2010.

[60] J. Dorn, V. Magdolen, A. Gkazepis et al., "Circulating biomarker tissue kallikrein-related peptidase KLK5 impacts ovarian cancer patients' survival," Annals of Oncology, vol. 22, no. 8, pp. 1783-1790, 2011.

[61] S. Dutta, F. Q. Wang, A. Phalen, and D. A. Fishman, "Biomarkers for ovarian cancer detection and therapy," Cancer Biology and Therapy, vol. 9, no. 9, pp. 666-675, 2010.

[62] P. Hartge, "Reducing ovarian cancer death rates through screening," Cancer, vol. 117, no. 3, pp. 449-450, 2011.

[63] I. Jacobs and U. Menon, "The Sine Qua Non of discovering novel biomarkers for early detection of ovarian cancer: carefully selected preclinical samples," Cancer Prevention Research, vol. 4, no. 3, pp. 299-302, 2011.

[64] Y. M. Kim, D. H. Whang, J. Park et al., "Evaluation of the accuracy of serum human epididymis protein 4 in combination with CA125 for detecting ovarian cancer: a prospective case-control study in a Korean population," Clinical Chemistry and Laboratory Medicine, vol. 49, no. 3, pp. 527534, 2011.

[65] T. S. Kristedja, R. J. Morgan, and M. Cristea, "Targeted agents in ovarian cancer," Women's Health, vol. 6, no. 5, pp. 679-694, 2010.

[66] J. A. Ledermann, C. Marth, M. S. Carey et al., "Role of molecular agents and targeted therapy in clinical trials for women with ovarian cancer," International Journal of Gynecological Cancer, vol. 21, no. 4, pp. 763-770, 2011.

[67] J. H. Lee, K. Park, Y. J. Chung et al., "AGR2, a mucinous ovarian cancer marker, promotes cell proliferation and 
migration," Experimental and Molecular Medicine, vol. 43, no. 2, pp. 91-100, 2011.

[68] S. Leskelä, L. J. Leandro-García, M. Mendiola et al., "The miR-200 family controls $\beta$-tubulin III expression and is associated with paclitaxel-based treatment response and progression-free survival in ovarian cancer patients," Endocrine-Related Cancer, vol. 18, no. 1, pp. 85-95, 2011.

[69] N. Liu, X. Wang, and X. Sheng, "'Triple negative' epithelial ovarian cancer and pathologic markers for prognosis," Current Opinion in Obstetrics and Gynecology, vol. 23, no. 1, pp. 19-23, 2010.

[70] C. L. Mitchell, J. P. B. O'connor, A. Jackson et al., "Identification of early predictive imaging biomarkers and their relationship to serological angiogenic markers in patients with ovarian cancer with residual disease following cytotoxic therapy," Annals of Oncology, vol. 21, no. 10, pp. 1982-1989, 2010.

[71] B. J.D. Rein, S. Gupta, R. Dada, J. Safi, C. Michener, and A. Agarwal, "Potential markers for detection and monitoring of ovarian cancer," Journal of Oncology, vol. 2011, Article ID 475983, 17 pages, 2011.

[72] J. Ren, H. Cai, Y. Li et al., "Tumor markers for early detection of ovarian cancer," Expert Review of Molecular Diagnostics, vol. 10, no. 6, pp. 787-798, 2010.

[73] C. S. Zhu, P. F. Pinsky, D. W. Cramer et al., "A framework for evaluating biomarkers for early detection: validation of biomarker panels for ovarian cancer," Cancer Prevention Research, vol. 4, no. 3, pp. 375-383, 2011.

[74] J. H. Hong, J. K. Lee, J. J. Park, N. W. Lee, K. W. Lee, and J. $\mathrm{Y}$. Na, "Expression pattern of the class I homeobox genes in ovarian carcinoma," Journal of Gynecologic Oncology, vol. 21, no. 1, pp. 29-37, 2010.

[75] J. Li, C. A. Sherman-Baust, M. Tsai-Turton, R. E. Bristow, R. B. Roden, and P. J. Morin, "Claudin-containing exosomes in the peripheral circulation of women with ovarian cancer," BMC cancer, vol. 9, p. 244, 2009.

[76] L. Bombardelli and U. Cavallaro, "Immunoglobulin-like cell adhesion molecules: novel signaling players in epithelial ovarian cancer," International Journal of Biochemistry and Cell Biology, vol. 42, no. 5, pp. 590-594, 2010.

[77] P. De Graeff, A. P. G. Crijns, K. A. Ten Hoor et al., "The ErbB signalling pathway: protein expression and prognostic value in epithelial ovarian cancer," British Journal of Cancer, vol. 99, no. 2, pp. 341-349, 2008.

[78] D. Faratian, A. J.M. Zweemer, Y. Nagumo et al., "Trastuzumab and pertuzumab produce changes in morphology and estrogen receptor signaling in ovarian cancer xenografts revealing new treatment strategies," Clinical Cancer Research, vol. 17, no. 13, pp. 4451-4461, 2011.

[79] D. Gallo, C. Ferlini, and G. Scambia, "The epithelialmesenchymal transition and the estrogen-signaling in ovarian cancer," Current Drug Targets, vol. 11, no. 4, pp. 474-481, 2010.

[80] L. Hernandez, S. C. Hsu, B. Davidson, M. J. Birrer, E. C. Kohn, and C. M. Annunziata, "Activation of NF- $\kappa$ B signaling by inhibitor of NF- $\kappa$ B kinase $\beta$ increases aggressiveness of ovarian cancer," Cancer Research, vol. 70, no. 10, pp. 40054014, 2010.

[81] K. Hua, J. Din, Q. Cao et al., "Estrogen and progestin regulate HIF- $1 \alpha$ expression in ovarian cancer cell lines via the activation of Akt signaling transduction pathway," Oncology Reports, vol. 21, no. 4, pp. 893-898, 2009.
[82] M. Ivan and D. Matei, "Blockade of FGF signaling: therapeutic promise for ovarian cancer," Cancer Biology and Therapy, vol. 10, no. 5, pp. 505-508, 2010.

[83] S. Mabuchi, T. Hisamatsu, and T. Kimura, "Targeting mTOR signaling pathway in ovarian cancer," Current Medicinal Chemistry, vol. 18, no. 19, pp. 2960-2968, 2011.

[84] J. H. No, Y. T. Jeon, I. A. Park et al., "Activation of mTOR signaling pathway associated with adverse prognostic factors of epithelial ovarian cancer," Gynecologic Oncology, vol. 121, no. 1, pp. 8-12, 2011.

[85] S. L. Rose, M. Kunnimalaiyaan, J. Drenzek, and N. Seiler, "Notch 1 signaling is active in ovarian cancer," Gynecologic Oncology, vol. 117, no. 1, pp. 130-133, 2010.

[86] H. Y. Su, H. C. Lai, Y. W. Lin et al., "Epigenetic silencing of SFRP5 is related to malignant phenotype and chemoresistance of ovarian cancer through Wnt signaling pathway," International Journal of Cancer, vol. 127, no. 3, pp. 555-567, 2010.

[87] J. Wang, J. Cai, F. Han et al., "Silencing of CXCR4 blocks progression of ovarian cancer and depresses canonical wnt signaling pathway," International Journal of Gynecological Cancer, vol. 21, no. 6, pp. 981-987, 2011.

[88] K. L. White, D. N. Rider, K. R. Kalli, K. L. Knutson, G. P. Jarvik, and E. L. Goode, "Genomics of the NF- $\kappa$ B signaling pathway: hypothesized role in ovarian cancer," Cancer Causes and Control, vol. 22, no. 5, pp. 785-801, 2011.

[89] S. Yamamura, N. Matsumura, M. Mandai et al., "The activated transforming growth factor-beta signaling pathway in peritoneal metastases is a potential therapeutic target in ovarian cancer," International Journal of Cancer, vol. 130, no. 1, pp. 20-28, 2012.

[90] K. T. Yeh, T. H. Chen, H. W. Yang et al., "Aberrant TGFbeta/SMAD4 signaling contributes to epigenetic silencing of a putative tumor suppressor, RunX1T1 in ovarian cancer," Epigenetics, vol. 6, no. 6, pp. 727-739, 2011.

[91] S. Zecchini, L. Bombardelli, A. Decio et al., "The adhesion molecule NCAM promotes ovarian cancer progression via FGFR signalling," EMBO Molecular Medicine, vol. 3, no. 8, pp. 480-494, 2011.

[92] H. Y. Zhang, P. N. Zhang, and H. Sun, "Aberration of the $\mathrm{PI} 3 \mathrm{~K} / \mathrm{AKT} / \mathrm{mTOR}$ signaling in epithelial ovarian cancer and its implication in cisplatin-based chemotherapy," European Journal of Obstetrics Gynecology and Reproductive Biology, vol. 146, no. 1, pp. 81-86, 2009.

[93] X. Zhang, J. George, S. Deb et al., "The Hippo pathway transcriptional co-activator, YAP, is an ovarian cancer oncogene," Oncogene, vol. 30, no. 25, pp. 2810-2822, 2011.

[94] Z. Zhao, X. F. Liu, H. C. Wu et al., "Rab5a overexpression promoting ovarian cancer cell proliferation may be associated with APPL1-related epidermal growth factor signaling pathway," Cancer Science, vol. 101, no. 6, pp. 1454-1462, 2010.

[95] R. N. Eskander and L. M. Randall, "Bevacizumab in the treatment of ovarian cancer," Biologics: Targets and Therapy, vol. 5, pp. 1-5, 2011.

[96] G. J. Gardner and E. L. Jewell, "Current and future directions of clinical trials for ovarian cancer," Cancer Control, vol. 18, no. 1, pp. 44-51, 2011.

[97] R. S. Mannel, M. F. Brady, E. C. Kohn et al., "A randomized phase III trial of IV carboplatin and paclitaxel x 3 courses followed by observation versus weekly maintenance low-dose paclitaxel in patients with early-stage ovarian carcinoma: 
a Gynecologic Oncology Group Study," Gynecologic Oncology, vol. 122, no. 1, pp. 89-94, 2011.

[98] D. G.K. Teoh and A. A. Secord, "Antiangiogenic therapies in epithelial ovarian cancer," Cancer Control, vol. 18, no. 1, pp. 31-43, 2011.

[99] M. S. Anglesio, M. S. Carey, M. Köbel, H. MacKay, and D. G. Huntsman, "Clear cell carcinoma of the ovary: a report from the first ovarian clear cell symposium, June 24th, 2010," Gynecologic Oncology, vol. 121, no. 2, pp. 407-415, 2011.

[100] C. H. Han, Y. J. Huang, K. H. Lu et al., "Polymorphisms in the SULF1 gene are associated with early age of onset and survival of ovarian cancer," Journal of Experimental \& Clinical Cancer Research, vol. 30, no. 1, p. 5, 2011.

[101] M. Konecny, M. Milly, K. Zavodna et al., "Comprehensive genetic characterization of hereditary breast/ovarian cancer families from Slovakia," Breast Cancer Research and Treatment, vol. 126, no. 1, pp. 119-130, 2011.

[102] P. A. Konstantinopoulos, D. Spentzos, B. Y. Karlan et al., "Gene expression profile of BRCAness that correlates with responsiveness to chemotherapy and with outcome in patients with epithelial ovarian cancer," Journal of Clinical Oncology, vol. 28, no. 22, pp. 3555-3561, 2010.

[103] J. Z. Press, A. De Luca, N. Boyd et al., "Ovarian carcinomas with genetic and epigenetic BRCA1 loss have distinct molecular abnormalities," BMC Cancer, vol. 8, article no. 17, 2008.

[104] A. Tinelli, A. Malvasi, G. Leo et al., "Hereditary ovarian cancers: from BRCA mutations to clinical management. A modern appraisal," Cancer and Metastasis Reviews, vol. 29, no. 2, pp. 339-350, 2010.

[105] E. Burton, D. Chase, M. Yamamoto, J. De Guzman, D. Imagawa, and M. L. Berman, "Surgical management of recurrent ovarian cancer: the advantage of collaborative surgical management and a multidisciplinary approach," Gynecologic Oncology, vol. 120, no. 1, pp. 29-32, 2011.

[106] A. Malek and O. Tchernitsa, "Evaluation of targets for ovarian cancer gene silencing therapy: in vitro and in vivo approaches," Methods in Molecular Biology, vol. 623, pp. 423436, 2010.

[107] D. Vergara, A. Tinelli, R. Martignago, A. Malvasi, V. E. Chiuri, and G. Leo, "Biomolecular pathogenesis of borderline ovarian tumors: Focusing target discovery through proteogenomics," Current Cancer Drug Targets, vol. 10, no. 1, pp. 107-116, 2010.

[108] C. L. Chang, B. Ma, X. Pang, T. C. Wu, and C.-F. Hung, "Treatment with cyclooxygenase-2 inhibitors enables repeated administration of vaccinia virus for vontrol of ovarian cancer," Molecular Therapy, vol. 17, no. 8, pp. 13651372, 2009.

[109] Y. Q. Zhang, Y. C. Tsai, A. Monie, T. C. Wu, and C. F. Hung, "Enhancing the therapeutic effect against ovarian cancer through a combination of viral oncolysis and antigen-specific immunotherapy," Molecular Therapy, vol. 18, no. 4, pp. 692699, 2010.

[110] A. Agarwal, S. L. Tressel, R. Kaimal et al., "Identification of a metalloprotease-chemokine signaling system in the ovarian cancer microenvironment: implications for antiangiogenic therapy," Cancer Research, vol. 70, no. 14, pp. 5880-5890, 2010.

[111] P. H. Anborgh, J. C. Mutrie, A. B. Tuck, and A. F. Chambers, "Role of the metastasis-promoting protein osteopontin in the tumour microenvironment," Journal of Cellular and Molecular Medicine, vol. 14, no. 8, pp. 2037-2044, 2010.
[112] N. Chan, I. M. Pires, Z. Bencokova et al., "Contextual synthetic lethality of cancer cell kill based on the tumor microenvironment," Cancer Research, vol. 70, no. 20, pp. 8045-8054, 2010.

[113] E. Dean, L. El-Helw, and J. Hasan, "Targeted therapies in epithelial ovarian cancer," Cancers, vol. 2, no. 1, pp. 88-113, 2010.

[114] E. S. Han, P. Lin, and M. Wakabayashi, "Current status on biologic therapies in the treatment of epithelial ovarian cancer," Current Treatment Options in Oncology, vol. 10, no. 1-2, pp. 54-66, 2009.

[115] D. Hanahan and R. A. Weinberg, "Hallmarks of cancer: the next generation," Cell, vol. 144, no. 5, pp. 646-674, 2011.

[116] V. Kruse, S. Rottey, O. De Backer, S. Van Belle, V. Cocquyt, and H. Denys, "PARP inhibitors in oncology: a new synthetic lethal approach to cancer therapy," Acta Clinica Belgica, vol. 66, no. 1, pp. 2-9, 2011.

[117] Y. Wang and G. Giaccone, "Challenges in cancer molecular targets and therapeutics," Frontiers in Oncology, vol. 1, article 4, pp. 1-3, 2011.

[118] Y. Yuan, Y. M. Liao, C. -T. Hsueh, and H. R. Mirshahidi, "Novel targeted therapeutics: inhibitors of MDM2, ALK and PARP," Journal of Hematology and Oncology, vol. 4, 2011.

[119] D. Gioeli, "The dynamics of the cell signaling network; implications for targeted therapies," in Targeted Therapies, D. Gioeli, Ed., pp. 33-53, Humana Press, New York, NY, USA, 2011.

[120] T. A. Yap, C. P. Carden, and S. B. Kaye, "Beyond chemotherapy: targeted therapies in ovarian cancer," Nature Reviews Cancer, vol. 9, no. 3, pp. 167-181, 2009.

[121] B. M. Norquist, R. L. Garcia, K. H. Allison et al., "The molecular pathogenesis of hereditary ovarian carcinoma," Cancer, vol. 116, no. 22, pp. 5261-5271, 2010.

[122] J. Z. Press, K. Wurz, B. M. Norquist et al., "Identification of a preneoplastic gene expression profile in tubal epithelium of BRCA1 mutation carriers," Neoplasia, vol. 12, no. 12, pp. 993-1002, 2010.

[123] K. Yoshihara, A. Tajima, S. Adachi et al., "Germline copy number variations in BRCA1-associated ovarian cancer patients," Genes Chromosomes and Cancer, vol. 50, no. 3, pp. 167-177, 2011.

[124] S. Zhang, R. Royer, S. Li et al., "Frequencies of BRCA1 and BRCA2 mutations among 1,342 unselected patients with invasive ovarian cancer," Gynecologic Oncology, vol. 121, no. 2, pp. 353-357, 2011.

[125] R. C. Bast Jr., "Status of tumor markers in ovarian cancer screening," Journal of Clinical Oncology, vol. 21, no. 10, supplement, pp. 200S-205S, 2003.

[126] S. Jie, L. Medico, and H. Zhao, "Allelic imbalance in BRCA1 and BRCA2 gene expression and familial ovarian cancer," Cancer Epidemiology Biomarkers and Prevention, vol. 20, no. 1, pp. 50-56, 2011.

[127] C. E. Wakefield, P. Ratnayake, B. Meiser et al., "'For all my family's sake, i should go and find out": an Australian report on genetic counseling and testing uptake in individuals at high risk of breast and/or ovarian cancer," Genetic Testing and Molecular Biomarkers, vol. 15, no. 6, pp. 379-385, 2011.

[128] P. C. Fong, D. S. Boss, T. A. Yap et al., "Inhibition of poly(ADP-ribose) polymerase in tumors from BRCA mutation carriers," New England Journal of Medicine, vol. 361, no. 2, pp. 123-134, 2009.

[129] H. Liang and A. R. Tan, "PARP inhibitors," Current Breast Cancer Reports, vol. 3, no. 1, pp. 44-54, 2011. 
[130] A. Mangerich and A. Bürkle, "How to kill tumor cells with inhibitors of poly(ADP-ribosyl)ation," International Journal of Cancer, vol. 128, no. 2, pp. 251-265, 2011.

[131] C. Underhill, M. Toulmonde, and H. Bonnefoi, "A review of PARP inhibitors: from bench to bedside," Annals of Oncology, vol. 22, no. 2, pp. 268-279, 2011.

[132] J. Weberpals, K. Garbuio, A. O’Brien et al., “The DNA repair proteins BECA1 and EECC1 as predictive markers In sporadic ovarian cancer," International Journal of Cancer, vol. 124, no. 4, pp. 806-815, 2009.

[133] A. Aly and S. Ganesan, "BRCA1, PARP, and 53BP1: conditional synthetic lethality and synthetic viability," Journal of Molecular Cell Biology, vol. 3, no. 1, pp. 66-74, 2011.

[134] A. Ashworth, "Drug resistance caused by reversion mutation," Cancer Research, vol. 68, no. 24, pp. 10021-10023, 2008.

[135] K. K. Dhillon, E. M. Swisher, and T. Taniguchi, "Secondary mutations of BRCA1/2 and drug resistance," Cancer Science, vol. 102, no. 4, pp. 663-669, 2011.

[136] W. Sakai, E. M. Swisher, B. Y. Karlan et al., "Secondary mutations as a mechanism of cisplatin resistance in BRCA2mutated cancers," Nature, vol. 451, no. 7182, pp. 1116-1120, 2008.

[137] E. M. Swisher, W. Sakai, B. Y. Karlan, K. Wurz, N. Urban, and T. Taniguchi, "Secondary BRCA1 mutations in BRCA1mutated ovarian carcinomas with platinum resistance," Cancer Research, vol. 68, no. 8, pp. 2581-2586, 2008.

[138] T. A. Yap, S. K. Sandhu, C. P. Carden, and J. S. de Bono, "Poly (ADP-ribose) polymerase (PARP) inhibitors: exploiting a synthetic lethal strategy in the clinic," CA Cancer Journal for Clinicians, vol. 61, no. 1, pp. 31-49, 2011.

[139] S. Rottenberg, J. E. Jaspers, A. Kersbergen et al., "High sensitivity of BRCA1-deficient mammary tumors to the PARP inhibitor AZD2281 alone and in combination with platinum drugs," Proceedings of the National Academy of Sciences of the United States of America, vol. 105, no. 44, pp. 17079-17084, 2008.

[140] D. A. Chan and A. J. Giaccia, "Harnessing synthetic lethal interactions in anticancer drug discovery," Nature Reviews Drug Discovery, vol. 10, no. 5, pp. 351-364, 2011.

[141] G. Peng and S. Y. Lin, "Exploiting the homologous recombination DNA repair network for targeted cancer therapy," World Journal of Clinical Oncology, vol. 2, no. 2, pp. 73-79, 2011.

[142] M. W. Audeh, J. Carmichael, R. T. Penson et al., "Oral poly(ADP-ribose) polymerase inhibitor olaparib in patients with BRCA1 or BRCA2 mutations and recurrent ovarian cancer: a proof-of-concept trial," The Lancet, vol. 376, no. 9737, pp. 245-251, 2010.

[143] C. M. Annunziata and J. O’Shaughnessy, "Poly (ADP-ribose) polymerase as a novel therapeutic target in cancer," Clinical Cancer Research, vol. 16, no. 18, pp. 4517-4526, 2010.

[144] D. S. Boss, J. H. Beijnen, and J. H. M. Schellens, "Inducing synthetic lethality using PARP inhibitors," Current Clinical Pharmacology, vol. 5, no. 3, pp. 192-195, 2010.

[145] R. Brough, J. R. Frankum, S. Costa-Cabral, C. J. Lord, and A. Ashworth, "Searching for synthetic lethality in cancer," Current Opinion in Genetics and Development, vol. 21, no. 1, pp. 34-41, 2011.

[146] C. P. Carden, T. A. Yap, and S. B. Kaye, "PARP inhibition: targeting the Achilles'heel of DNA repair to treat germline and sporadic ovarian cancers," Current Opinion in Oncology, vol. 22, no. 5, pp. 473-480, 2010.
[147] S. L. Chan and T. Mok, "PARP inhibition in BRCA-mutated breast and ovarian cancers," The Lancet, vol. 376, no. 9737, pp. 211-213, 2010.

[148] Y. Crawford and N. Ferrara, "Tumor and stromal pathways mediating refractoriness/resistance to anti-angiogenic therapies," Trends in Pharmacological Sciences, vol. 30, no. 12, pp. 624-630, 2009.

[149] B. Döme, M. J. C. Hendrix, S. Paku, J. Tóvári, and J. Tímár, "Alternative vascularization mechanisms in cancer: pathology and therapeutic implications," American Journal of Pathology, vol. 170, no. 1, pp. 1-15, 2007.

[150] N. Ferrara, "Pathways mediating VEGF-independent tumor angiogenesis," Cytokine and Growth Factor Reviews, vol. 21, no. 1, pp. 21-26, 2010.

[151] C. Francavilla, L. Maddaluno, and U. Cavallaro, "The functional role of cell adhesion molecules in tumor angiogenesis," Seminars in Cancer Biology, vol. 19, no. 5, pp. 298-309, 2009.

[152] A. Raza, M. J. Franklin, and A. Z. Dudek, "Pericytes and vessel maturation during tumor angiogenesis and metastasis," American Journal of Hematology, vol. 85, no. 8, pp. 593-598, 2010.

[153] W. A. Spannuth, A. K. Sood, and R. L. Coleman, "Angiogenesis as a strategic target for ovarian cancer therapy," Nature Clinical Practice Oncology, vol. 5, no. 4, pp. 194-204, 2008.

[154] F. P. Duhoux and J. P. Machiels, "Antivascular therapy for epithelial ovarian cancer," Journal of Oncology, vol. 2010, Article ID 372547, 16 pages, 2010.

[155] N. G. Gavalas, A. Karadimou, M. A. Dimopoulos, and A. Bamias, "Immune response in ovarian cancer: how is the immune system involved in prognosis and therapy: potential for treatment utilization," Clinical and Developmental Immunology, vol. 2010, Article ID 791603, 15 pages, 2010.

[156] G. C. Kumaran, G. C. Jayson, and A. R. Clamp, "Antiangiogenic drugs in ovarian cancer," British Journal of Cancer, vol. 100, no. 1, pp. 1-7, 2009.

[157] L. J. Willmott and J. P. Fruehauf, "Targeted therapy in ovarian cancer," Journal of Oncology, vol. 2010, Article ID 740472, 9 pages, 2010.

[158] F. Coilinson and G. Jayson, "New therapeutic agents in ovarian cancer," Current Opinion in Obstetrics and Gynecology, vol. 21, no. 1, pp. 44-53, 2009.

[159] T. de La Motte Rouge, M. C. Petrella, J. Michels et al., "New drugs and targeted therapeutic agents in ovarian cancer," Bulletin du Cancer, vol. 96, no. 12, pp. 1215-1224, 2009.

[160] L. A. Hefler, R. Zeillinger, C. Grimm et al., "Preoperative serum vascular endothelial growth factor as a prognostic parameter in ovarian cancer," Gynecologic Oncology, vol. 103, no. 2, pp. 512-517, 2006.

[161] C. Rudlowski, A. K. Pickart, C. Fuhljahn et al., "Prognostic significance of vascular endothelial growth factor expression in ovarian cancer patients: a long-term follow-up," International Journal of Gynecological Cancer, vol. 16, no. 1, pp. 183189, 2006.

[162] R. A. Burger, "Overview of anti-angiogenic agents in development for ovarian cancer," Gynecologic Oncology, vol. 121, no. 1, pp. 230-238, 2011.

[163] U. A. Matulonis, "Bevacizumab and its use in epithelial ovarian cancer," Future Oncology, vol. 7, no. 3, pp. 365-379, 2011.

[164] C. M. Annunziata, A. J. Walker, L. Minasian et al., "Vandetanib, designed to inhibit VEGFR2 and EGFR signaling, had no clinical activity as monotherapy for recurrent ovarian cancer and no detectable modulation of VEGFR2," Clinical Cancer Research, vol. 16, no. 2, pp. 664-672, 2010. 
[165] L. Bodnar, M. Górnas, and C. Szczylik, "Sorafenib as a third line therapy in patients with epithelial ovarian cancer or primary peritoneal cancer: a phase II study," Gynecologic Oncology, vol. 123, no. 1, pp. 33-36, 2011.

[166] D. Matei, M. W. Sill, H. A. Lankes et al., "Activity of sorafenib in recurrent ovarian cancer and primary peritoneal carcinomatosis: a gynecologic oncology group trial," Journal of Clinical Oncology, vol. 29, no. 1, pp. 69-75, 2011.

[167] J. Homsi and A. I. Daud, "Spectrum of activity and mechanism of action of VEGF/PDGF inhibitors," Cancer Control, vol. 14, no. 3, pp. 285-294, 2007.

[168] F. Shojaei and N. Ferrara, "Role of the microenvironment in tumor growth and in refractoriness/resistance to antiangiogenic therapies," Drug Resistance Updates, vol. 11, no. 6, pp. 219-230, 2008.

[169] B. A. Teicher, "Antiangiogenic agents and targets: a perspective," Biochemical Pharmacology, vol. 81, no. 1, pp. 6-12, 2011.

[170] G. Tortora, F. Ciardiello, and G. Gasparini, "Combined targeting of EGFR-dependent and VEGF-dependent pathways: rationale, preclinical studies and clinical applications," Nature Clinical Practice Oncology, vol. 5, no. 9, pp. 521-530, 2008.

[171] B. D. Gomperts, I. M. Kramer, and P. E. R. Tatham, "Signalling pathways operated by receptor protein tyrosine kinases," in Signal Transduction, pp. 315-374, Academic Press, San Diego, Calif, USA, 2009.

[172] J. Nelson, "Single pass growth factor receptors," in Structure and Function in Cell Signalling, pp. 179-214, Wiley, West Sussex, UK, 2008.

[173] R. C. Bast Jr., C. M. Boyer, I. Jacobs et al., "Cell growth regulation in epithelial ovarian cancer," Cancer, vol. 71, no. 4, pp. 1597-1601, 1993.

[174] F. Ciardiello and G. Tortora, "Drug therapy: EGFR antagonists in cancer treatment," New England Journal of Medicine, vol. 358, no. 11, pp. 1096-1174, 2008.

[175] K. D. Steffensen, M. Waldstrøm, U. Jeppesen, E. Jakobsen, I. Brandslund, and A. Jakobsen, "The prognostic importance of cyclooxygenase 2 and HER2 expression in epithelial ovarian cancer," International Journal of Gynecological Cancer, vol. 17, no. 4, pp. 798-807, 2007.

[176] A. T. Baron, J. M. Lafky, C. H. Boardman et al., "Soluble epidermal growth factor receptor: a biomarker of epithelial ovarian cancer," Cancer Treatment and Research, vol. 149, pp. 189-202, 2009.

[177] J. M. Lafky, J. A. Wilken, A. T. Baron, and N. J. Maihle, "Clinical implications of the ErbB/epidermal growth factor (EGF) receptor family and its ligands in ovarian cancer," Biochimica et Biophysica Acta. Reviews on Cancer, vol. 1785, no. 2, pp. 232-265, 2008.

[178] C. Bolitho, M. A. Hahn, R. C. Baxter, and D. J. Marsh, "The chemokine CXCL1 induces proliferation in epithelial ovarian cancer cells by transactivation of the epidermal growth factor receptor," Endocrine-Related Cancer, vol. 17, no. 4, pp. 929940, 2010.

[179] D. Reimer, M. Hubalek, S. Riedle et al., "E2F3a is critically involved in epidermal growth factor receptor-directed proliferation in ovarian cancer," Cancer Research, vol. 70, no. 11, pp. 4613-4623, 2010.

[180] L. G. Hudson, R. Zeineldin, M. Silberberg, and M. S. Stack, "Activated epidermal growth factor receptor in ovarian cancer," Cancer Treatment and Research, vol. 149, pp. 203226, 2009.
[181] L. P. Song, G. T. Hammond, and P. C. K. Leung, "Epidermal growth factor-induced GnRH-II synthesis contributes to ovarian cancer cell invasion," Molecular Endocrinology, vol. 23, no. 10, pp. 1646-1656, 2009.

[182] Y. Tanaka, Y. Terai, A. Tanabe et al., "Prognostic effect of epidermal growth factor receptor gene mutations and the aberrant phosphorylation of Akt and ERK in ovarian cancer," Cancer Biology and Therapy, vol. 11, no. 1, pp. 50-57, 2011.

[183] H. Y. Zhou, Y. L. Pon, and A. S. T. Wong, "Synergistic effects of epidermal growth factor and hepatocyte growth factor on human ovarian cancer cell invasion and migration: role of extracellular signal-regulated kinase $1 / 2$ and p38 mitogenactivated protein kinase," Endocrinology, vol. 148, no. 11, pp. 5195-5208, 2007.

[184] M. A. Bookman, K. M. Darcy, D. Clarke-Pearson, R. A. Boothby, and I. R. Horowitz, "Evaluation of monoclonal humanized anti-HER2 antibody, trastuzumab, in patients with recurrent or refractory ovarian or primary peritoneal carcinoma with overexpression of HER2: a phase II trial of the Gynecologic Oncology Group," Journal of Clinical Oncology, vol. 21, no. 2, pp. 283-290, 2003.

[185] S. Campos, O. Hamid, M. V. Seiden et al., "Multicenter, randomized phase II trial of oral CI-1033 for previously treated advanced ovarian cancer," Journal of Clinical Oncology, vol. 23, no. 24, pp. 5597-5604, 2005.

[186] A. N. Gordon, N. Finkler, R. P. Edwards et al., "Efficacy and safety of erlotinib $\mathrm{HCl}$, an epidermal growth factor receptor (HER1/EGFR) tyrosine kinase inhibitor, in patients with advanced ovarian carcinoma: results from a phase II multicenter study," International Journal of Gynecological Cancer, vol. 15, no. 5, pp. 785-792, 2005.

[187] M. S. Gordon, D. Matei, C. Aghajanian et al., "Clinical activity of pertuzumab (rhuMAb 2C4), a HER dimerization inhibitor, in advanced ovarian cancer: potential predictive relationship with tumor HER2 activation status," Journal of Clinical Oncology, vol. 24, no. 26, pp. 4324-4332, 2006.

[188] M. J. Palayekar and T. J. Herzog, "The emerging role of epidermal growth factor receptor inhibitors in ovarian cancer," International Journal of Gynecological Cancer, vol. 18, no. 5, pp. 879-890, 2008.

[189] J. Reibenwein and M. Krainer, "Targeting signaling pathways in ovarian cancer," Expert Opinion on Therapeutic Targets, vol. 12, no. 3, pp. 353-365, 2008.

[190] R. J. Schilder, M. W. Sill, X. Chen et al., "Phase II study of gefitinib in patients with relapsed or persistent ovarian or primary peritoneal carcinoma and evaluation of epidermal growth factor receptor mutations and immunohistochemical expression: a Gynecologic Oncology Group Study," Clinical Cancer Research, vol. 11, no. 15, pp. 5539-5548, 2005.

[191] A. A. Secord, J. A. Blessing, D. K. Armstrong et al., "Phase II trial of cetuximab and carboplatin in relapsed platinumsensitive ovarian cancer and evaluation of epidermal growth factor receptor expression: a Gynecologic Oncology Group study," Gynecologic Oncology, vol. 108, pp. 493-499, 2008.

[192] L. Tang and X. Zhao, "Polyclonal antitumor immunoglobulin may play a role in ovarian cancer adjuvant therapy," Medical Hypotheses, vol. 76, no. 4, pp. 530-532, 2011.

[193] U. Wagner, A. du Bois, J. Pfisterer et al., "Gefitinib in combination with tamoxifen in patients with ovarian cancer refractory or resistant to platinum-taxane based therapyA phase II trial of the AGO Ovarian Cancer Study Group (AGO-OVAR 2.6)," Gynecologic Oncology, vol. 105, no. 1, pp. 132-137, 2007. 
[194] R. Zeineldin, C. Y. Muller, M. S. Stack, and L. G. Hudson, "Targeting the EGF receptor for ovarian cancer therapy," Journal of Oncology, vol. 2010, Article ID 414676, 11 pages, 2010.

[195] C. Elie, J. F. Geay, M. Morcos et al., "Lack of relationship between EGFR-1 immunohistochemical expression and prognosis in a multicentre clinical trial of 93 patients with advanced primary ovarian epithelial cancer (GINECO group)," British Journal of Cancer, vol. 91, no. 3, pp. 470-475, 2004.

[196] J. S. Nielsen, E. Jakobsen, B. Hølund, K. Bertelsen, and A. Jakobsen, "Prognostic significance of p53, Her-2, and EGFR overexpression in borderline and epithelial ovarian cancer," International Journal of Gynecological Cancer, vol. 14, no. 6, pp. 1086-1096, 2004.

[197] A. Psyrri, M. Kassar, Z. Yu et al., "Effect of epidermal growth factor receptor expression level on survival in patients with epithelial ovarian cancer," Clinical Cancer Research, vol. 11, no. 24, pp. 8637-8643, 2005.

[198] E. M. Posadas, V. Kwitkowski, H. L. Kotz et al., "A prospective analysis of imatinib-induced c-KIT modulation in ovarian cancer: a phase II clinical study with proteomic profiling," Cancer, vol. 110, no. 2, pp. 309-317, 2007.

[199] E. M. Posadas, M. S. Liel, V. Kwitkowski et al., "A phase II and pharmacodynamic study of gefitinib in patients with refractory or recurrent epithelial ovarian cancer," Cancer, vol. 109, no. 7, pp. 1323-1330, 2007.

[200] H. Tsujioka, F. Yotsumoto, S. Hikita, T. Ueda, M. Kuroki, and S. Miyamoto, "Targeting the heparin-binding epidermal growth factor-like growth factor in ovarian cancer therapy," Current Opinion in Obstetrics and Gynecology, vol. 23, no. 1, pp. 24-30, 2011.

[201] H. Yagi, F. Yotsumoto, and S. Miyamoto, "Heparin-binding epidermal growth factor-like growth factor promotes transcoelomic metastasis in ovarian cancer through epithelial-mesenchymal transition," Molecular Cancer Therapeutics, vol. 7, no. 10, pp. 3441-3451, 2008.

[202] R. Bianco, S. Garofalo, R. Rosa et al., "Inhibition of mTOR pathway by everolimus cooperates with EGFR inhibitors in human tumours sensitive and resistant to anti-EGFR drugs," British Journal of Cancer, vol. 98, no. 5, pp. 923-930, 2008.

[203] K. J. Dedes, D. Wetterskog, A. Ashworth, S. B. Kaye, and J. S. Reis-Filho, "Emerging therapeutic targets in endometrial cancer," Nature Reviews Clinical Oncology, vol. 8, no. 5, pp. 261-271, 2011.

[204] H. Foster, H. M. Coley, A. Goumenou, G. Pados, A. Harvey, and E. Karteris, "Differential expression of mTOR signalling components in drug resistance in ovarian cancer," Anticancer Research, vol. 30, no. 9, pp. 3529-3534, 2010.

[205] X. B. Trinh, W. A. A. Tjalma, P. B. Vermeulen et al., "The VEGF pathway and the AKT/mTOR/p70S6K1 signalling pathway in human epithelial ovarian cancer," British Journal of Cancer, vol. 100, no. 6, pp. 971-978, 2009.

[206] H. A. Alshenawy, "Immunohistochemical expression of epidermal growth factor receptor, E-cadherin, and matrix metalloproteinase-9 in ovarian epithelial cancer and relation to patient deaths," Annals of Diagnostic Pathology, vol. 14, no. 6, pp. 387-395, 2010.

[207] R. Lim, N. Ahmed, N. Borregaard et al., "Neutrophil gelatinase-associated lipocalin (NGAL) an early-screening biomarker for ovarian cancer: NGAL is associated with epidermal growth factor-induced epithelio-mesenchymal transition," International Journal of Cancer, vol. 120, no. 11, pp. 2426-2434, 2007.
[208] J. Morrison, S. S. Briggs, N. K. Green et al., "Cetuximab retargeting of adenovirus via the epidermal growth factor receptor for treatment of intraperitoneal ovarian cancer," Human Gene Therapy, vol. 20, no. 3, pp. 239-251, 2009.

[209] Q. Sheng and J. Liu, "The therapeutic potential of targeting the EGFR family in epithelial ovarian cancer," British Journal of Cancer, vol. 104, no. 8, pp. 1241-1245, 2011.

[210] D. R. Siwak, M. Carey, B. T. Hennessy et al., "Targeting the epidermal growth factor receptor in epithelial ovarian cancer: current knowledge and future challenges," Journal of Oncology, vol. 2010, Article ID 568938, 20 pages, 2010.

[211] S. C. Chauhan, D. Kumar, and M. Jaggi, "Mucins in ovarian cancer diagnosis and therapy," Journal of Ovarian Research, vol. 2, no. 1, article no. 21, 2009.

[212] V. A. Heinzelmann-Schwarz, M. Gardiner-Garden, S. M. Henshall et al., "A distinct molecular profile associated with mucinous epithelial ovarian cancer," British Journal of Cancer, vol. 94, no. 6, pp. 904-913, 2006.

[213] N. Jonckheere and I. van Seuningen, "The membrane-bound mucins: from cell signalling to transcriptional regulation and expression in epithelial cancers," Biochimie, vol. 92, no. 1, pp. $1-11,2010$.

[214] M. R. Andersen, B. A. Goff, K. A. Lowe et al., "Use of a Symptom Index, CA125, and HE4 to predict ovarian cancer," Gynecologic Oncology, vol. 116, no. 3, pp. 378-383, 2010.

[215] D. W. Cramer, D. J. O’Rourke, A. F. Vitonis et al., "CA125 immune complexes in ovarian cancer patients with low CA125 concentrations," Clinical Chemistry, vol. 56, no. 12, pp. 1889-1892, 2010.

[216] N. D. Fleming, I. Cass, C. S. Walsh, B. Y. Karlan, and A. J. Li, "CA125 surveillance increases optimal resectability at secondary cytoreductive surgery for recurrent epithelial ovarian cancer," Gynecologic Oncology, vol. 121, no. 2, pp. 249-252, 2011.

[217] M. Montagnana, E. Danese, O. Ruzzenente et al., "The ROMA (Risk of Ovarian Malignancy Algorithm) for estimating the risk of epithelial ovarian cancer in women presenting with pelvic mass: is it really useful?" Clinical Chemistry and Laboratory Medicine, vol. 49, no. 3, pp. 521-525, 2011.

[218] J. A. Rauh-Hain, T. C. Krivak, M. G. del Carmen, and A. B. Olawaiye, "Ovarian cancer screening and early detection in the general population," Reviews in Obstetrics and Gynecology, vol. 4, no. 1, pp. 15-21, 2011.

[219] C. A. Shah, K. A. Lowe, P. Paley et al., "Influence of ovarian cancer risk status on the diagnostic performance of the serum biomarkers mesothelin, HE4, and CA125," Cancer Epidemiology Biomarkers and Prevention, vol. 18, no. 5, pp. 1365-1372, 2009.

[220] T. Van Gorp, I. Cadron, E. Despierre et al., "HE4 and CA125 as a diagnostic test in ovarian cancer: prospective validation of the risk of ovarian malignancy algorithm," British Journal of Cancer, vol. 104, no. 5, pp. 863-870, 2011.

[221] C. van Haaften-Day, Y. Shen, F. Xu et al., "OVXL, macrophage-colony stimulating factor, and CA-125-II as tumor markers for epithelial ovarian carcinoma a critical appraisal," Cancer, vol. 92, no. 11, pp. 2837-2844, 2001.

[222] C. Thériault, M. Pinard, M. Comamala et al., "MUC16 (CA125) regulates epithelial ovarian cancer cell growth, tumorigenesis and metastasis," Gynecologic Oncology, vol. 121, no. 3, pp. 434-443, 2011.

[223] M. Boivin, D. Lane, A. Piché, and C. Rancourt, "CA125 (MUC16) tumor antigen selectively modulates the sensitivity of ovarian cancer cells to genotoxic drug-induced apoptosis," Gynecologic Oncology, vol. 115, no. 3, pp. 407-413, 2009. 
[224] J. A. A. Gubbels, J. Belisle, M. Onda et al., "MesothelinMUC16 binding is a high affinity, N-glycan dependent interaction that facilitates peritoneal metastasis of ovarian tumors," Molecular Cancer, vol. 5, article no. 50, 2006.

[225] A. Rump, Y. Morikawa, M. Tanaka et al., "Binding of ovarian cancer antigen CA125/MUC61 to mesothelin mediates cell adhesion," Journal of Biological Chemistry, vol. 279, no. 10, pp. 9190-9198, 2004.

[226] J. A. Belisle, J. A. A. Gubbels, C. A. Raphael et al., "Peritoneal natural killer cells from epithelial ovarian cancer patients show an altered phenotype and bind to the tumour marker MUC16 (CA125)," Immunology, vol. 122, no. 3, pp. 418-429, 2007.

[227] Y. Chen, S. Clark, T. Wong et al., "Armed antibodies targeting the mucin repeats of the ovarian cancer antigen, MUC16, are highly efficacious in animal tumor models," Cancer Research, vol. 67, no. 10, pp. 4924-4932, 2007.

[228] S. A. McQuarrie, J. R. Mercer, A. Syme, M. R. Suresh, and G. G. Miller, "Preliminary results of nanopharmaceuticals used in the radioimmunotheraphy of ovarian cancer," Journal of Pharmacy and Pharmaceutical Sciences, vol. 7, no. 4, pp. 2934, 2005.

[229] N. Scholler and N. Urban, "CA125 in ovarian cancer," Biomarkers in Medicine, vol. 1, no. 4, pp. 513-523, 2007.

[230] A. A. Chekmasova, T. D. Rao, Y. Nikhamin et al., "Successful eradication of established peritoneal ovarian tumors in SCID-Beige mice following adoptive transfer of $\mathrm{T}$ cells genetically targeted to the MUC16 antigen," Clinical Cancer Research, vol. 16, no. 14, pp. 3594-3606, 2010.

[231] M. O. Lasaro and H. C. J. Ertl, "Targeting inhibitory pathways in cancer immunotherapy," Current Opinion in Immunology, vol. 22, no. 3, pp. 385-390, 2010.

[232] T. Zhang and D. Herlyn, "Combination of active specific immunotherapy or adoptive antibody or lymphocyte immunotherapy with chemotherapy in the treatment of cancer," Cancer Immunology, Immunotherapy, vol. 58, no. 4, pp. 475-492, 2009.

[233] S. Rachagani, M. P. Torres, N. Moniaux, and S. K. Batra, "Current status of mucins in the diagnosis and therapy of cancer," BioFactors, vol. 35, no. 6, pp. 509-527, 2009.

[234] A. P. Singh, S. Senapati, M. P. Ponnusamy et al., "Clinical potential of mucins in diagnosis, prognosis, and therapy of ovarian cancer," The Lancet Oncology, vol. 9, no. 11, pp. 1076$1085,2008$.

[235] T. Edgell, G. Martin-Roussety, G. Barker et al., "Phase II biomarker trial of a multimarker diagnostic for ovarian cancer," Journal of Cancer Research and Clinical Oncology, vol. 136, no. 7, pp. 1079-1088, 2010.

[236] F. J. Xu, Y. H. Yu, L. Daly et al., "OVX1 as a marker for early stage endometrial carcinoma," Cancer, vol. 73, no. 7, pp. 1855-1858, 1994.

[237] F. J. Xu, Y. H. Yu, L. Daly et al., "OVX1 radioimmunoassay complements CA-125 for predicting the presence of residual ovarian carcinoma at second-look surgical surveillance procedures," Journal of Clinical Oncology, vol. 11, no. 8, pp. 1506-1510, 1993.

[238] F. J. Xu, Y. H. Yu, B. Y. Li et al., "Development of two new monoclonal antibodies reactive to a surface antigen present on human ovarian epithelial cancer cells," Cancer Research, vol. 51, no. 15, pp. 4012-4019, 1991.

[239] C. N. Baxevanis, S. A. Perez, and M. Papamichail, "Combinatorial treatments including vaccines, chemotherapy and monoclonal antibodies for cancer therapy," Cancer Immunology, Immunotherapy, vol. 58, no. 3, pp. 317-324, 2009.
[240] A. B. Frey and N. Monu, "Signaling defects in anti-tumor T cells," Immunological Reviews, vol. 222, no. 1, pp. 192-205, 2008.

[241] M. Mathew and R. S. Verma, "Humanized immunotoxins: a new generation of immunotoxins for targeted cancer therapy," Cancer Science, vol. 100, no. 8, pp. 1359-1365, 2009.

[242] L. Gao, L. Yan, B. Lin et al., "Enhancive effects of Lewis y antigen on CD44-mediated adhesion and spreading of human ovarian cancer cell line RMG-I," Journal of Experimental and Clinical Cancer Research, vol. 30, no. 1, p. 15, 2011.

[243] T. V. Clendenen, E. Lundin, A. Zeleniuch-Jacquotte et al., "Circulating inflammation markers and risk of epithelial ovarian cancer," Cancer Epidemiology Biomarkers and Prevention, vol. 20, no. 5, pp. 799-810, 2011.

[244] R. L. Giuntoli, T. J. Webb, A. Zoso et al., "Ovarian cancerassociated ascites demonstrates altered immune environment: implications for antitumor immunity," Anticancer Research, vol. 29, no. 8, pp. 2875-2884, 2009.

[245] S. Kim, A. Hagemann, and A. Demichele, "Immunomodulatory gene polymorphisms and outcome in breast and ovarian cancer," Immunological Investigations, vol. 38, no. 34, pp. 324-340, 2009.

[246] H. Kulbe, R. Thompson, J. L. Wilson et al., "The inflammatory cytokine tumor necrosis factor- $\alpha$ generates an autocrine tumor-promoting network in epithelial ovarian cancer cells," Cancer Research, vol. 67, no. 2, pp. 585-592, 2007.

[247] A. L. Leizer, A. B. Alvero, H. H. Fu et al., "Regulation of inflammation by the NF- $\kappa$ B pathway in ovarian cancer stem cells," American Journal of Reproductive Immunology, vol. 65, no. 4, pp. 438-447, 2011.

[248] W. W. Lin and M. Karin, "A cytokine-mediated link between innate immunity, inflammation, and cancer," Journal of Clinical Investigation, vol. 117, no. 5, pp. 1175-1183, 2007.

[249] G. Mor, G. Yin, I. Chefetz, Y. Yang, and A. Alvero, "Ovarian cancer stem cells and inflammation," Cancer Biology and Therapy, vol. 11, no. 8, pp. 708-713, 2011.

[250] M. Nowak, E. Glowacka, M. Szpakowski et al., "Proinflammatory and immunosuppressive serum, ascites and cyst fluid cytokines in patients with early and advanced ovarian cancer and benign ovarian tumors," Neuroendocrinology Letters, vol. 31, no. 3, pp. 375-383, 2010.

[251] R. Yigit, C. G. Figdor, P. L.M. Zusterzeel, J. M. Pots, R. Torensma, and L. F.A.G. Massuger, "Cytokine analysis as a tool to understand tumour-host interaction in ovarian cancer," European Journal of Cancer, vol. 47, no. 12, pp. 18831889, 2011.

[252] J. Bollrath and F. R. Greten, "IKK/NF-B and STAT3 pathways: central signalling hubs in inflammation-mediated tumour promotion and metastasis," EMBO Reports, vol. 10, no. 12, pp. 1314-1319, 2009.

[253] Z. Duan, R. Y. Ames, M. Ryan, F. J. Hornicek, H. Mankin, and M. V. Seiden, "CDDO-Me, a synthetic triterpenoid, inhibits expression of IL-6 and Stat3 phosphorylation in multi-drug resistant ovarian cancer cells," Cancer Chemotherapy and Pharmacology, vol. 63, no. 4, pp. 681-689, 2009.

[254] Z. Duan, R. Foster, D. A. Bell et al., "Signal transducers and activators of transcription 3 pathway activation in drugresistant ovarian cancer," Clinical Cancer Research, vol. 12, no. 17, pp. 5055-5063, 2006.

[255] S. Grivennikov and M. Karin, "Autocrine IL-6 signaling: a key event in tumorigenesis?" Cancer Cell, vol. 13, no. 1, pp. 7-9, 2008. 
[256] S. I. Grivennikov and M. Karin, "Dangerous liaisons: STAT3 and NF- $\kappa \mathrm{B}$ collaboration and crosstalk in cancer," Cytokine and Growth Factor Reviews, vol. 21, no. 1, pp. 11-19, 2010.

[257] D. R. Hodge, E. M. Hurt, and W. L. Farrar, "The role of IL-6 and STAT3 in inflammation and cancer," European Journal of Cancer, vol. 41, no. 16, pp. 2502-2512, 2005.

[258] H. Yu, D. Pardoll, and R. Jove, "STATs in cancer inflammation and immunity: a leading role for STAT3," Nature Reviews Cancer, vol. 9, no. 11, pp. 798-809, 2009.

[259] Y. Wang, X. L. Niu, Y. Qu et al., "Autocrine production of interleukin-6 confers cisplatin and paclitaxel resistance in ovarian cancer cells," Cancer Letters, vol. 295, no. 1, pp. 110 $123,2010$.

[260] D. Lane, I. Matte, C. Rancourt, and A. Piché, "Prognostic significance of IL-6 and IL-8 ascites levels in ovarian cancer patients," BMC Cancer, vol. 11, p. 210, 2011.

[261] Y. Guo, J. Nemeth, C. O’Brien et al., "Effects of siltuximab on the IL-6-induced signaling pathway in ovarian cancer," Clinical Cancer Research, vol. 16, no. 23, pp. 5759-5769, 2010.

[262] C. W. Lo, M. W. Chen, M. Hsiao et al., "IL-6 trans-signaling in formation and progression of malignant ascites in ovarian cancer," Cancer Research, vol. 71, no. 2, pp. 424-434, 2011.

[263] M. Colomiere, J. Findlay, L. Ackland, and N. Ahmed, "Epidermal growth factor-induced ovarian carcinoma cell migration is associated with JAK2/STAT3 signals and changes in the abundance and localization of $\alpha 6 \beta 1$ integrin," International Journal of Biochemistry and Cell Biology, vol. 41, no. 5, pp. 1034-1045, 2009.

[264] M. Colomiere, A. C. Ward, C. Riley et al., "Cross talk of signals between EGFR and IL-6R through JAK2/STAT3 mediate epithelial-mesenchymal transition in ovarian carcinomas," British Journal of Cancer, vol. 100, no. 1, pp. 134-144, 2009.

[265] V. Baud and M. Karin, "Is NF- $\kappa$ B a good target for cancer therapy? Hopes and pitfalls," Nature Reviews Drug Discovery, vol. 8, no. 1, pp. 33-40, 2009.

[266] M. M. Chaturvedi, B. Sung, V. R. Yadav, R. Kannappan, and B. B. Aggarwal, "NF- $\kappa$ B addiction and its role in cancer: one size does not fit all," Oncogene, vol. 30, no. 14, pp. 1615-1630, 2011.

[267] L. Kleinberg, H. P. Dong, A. Holth et al., "Cleaved caspase3 and nuclear factor- $\kappa \mathrm{B}$ p65 are prognostic factors in metastatic serous ovarian carcinoma," Human Pathology, vol. 40, no. 6, pp. 795-806, 2009.

[268] X. Fang, S. Yu, R. C. Bast et al., "Mechanisms for lysophosphatidic acid-induced cytokine production in ovarian cancer cells," Journal of Biological Chemistry, vol. 279, no. 10, pp. 9653-9661, 2004.

[269] W. M. Merritt, Y. G. Lin, W. A. Spannuth et al., "Effect of interleukin-8 gene silencing with liposome-encapsulated small interfering RNA on ovarian cancer cell growth," Journal of the National Cancer Institute, vol. 100, no. 5, pp. 359-372, 2008.

[270] B. M. Schwartz, G. Hong, B. H. Morrison et al., "Lysophospholipids increase interleukin-8 expression in ovarian cancer cells," Gynecologic Oncology, vol. 81, no. 2, pp. 291-300, 2001.

[271] D. J. J. Waugh and C. Wilson, "The interleukin-8 pathway in cancer," Clinical Cancer Research, vol. 14, no. 21, pp. 67356741, 2008.

[272] L. Xu and I. J. Fidler, "Interleukin 8: an autocrine growth factor for human ovarian cancer," Oncology Research, vol. 12, no. 2, pp. 97-106, 2000.

[273] J. Yang, Y. Wang, Y. Gao, J. Shao, X. J. Zhang, and Z. Yao, "Reciprocal regulation of $17 \beta$-estradiol, interleukin- 6 and interleukin-8 during growth and progression of epithelial ovarian cancer," Cytokine, vol. 46, no. 3, pp. 382-391, 2009.

[274] L. F. Lee, R. P. Hellendall, Y. Wang et al., "IL-8 reduced tumorigenicity of human ovarian cancer in vivo due to neutrophil infiltration," Journal of Immunology, vol. 164, no. 5, pp. 2769-2775, 2000.

[275] K. M. Schmeler, S. Vadhan-Raj, P. T. Ramirez et al., "A phase II study of GM-CSF and rIFN- $\gamma$ 1b plus carboplatin for the treatment of recurrent, platinum-sensitive ovarian, fallopian tube and primary peritoneal cancer," Gynecologic Oncology, vol. 113, no. 2, pp. 210-215, 2009.

[276] F. Brimo, M. Herawi, R. Sharma, G. J. Netto, J. I. Epstein, and P. B. Illei, "Hepatocyte nuclear factor- $1 \beta$ expression in clear cell adenocarcinomas of the bladder and urethra: diagnostic utility and implications for histogenesis," Human Pathology, vol. 42, no. 11, pp. 1613-1619, 2011.

[277] A. Higashiguchi, T. Yamada, N. Susumu et al., "Specific expression of hepatocyte nuclear factor- $1 \beta$ in the ovarian clear cell adenocarcinoma and its application to cytological diagnosis," Cancer Science, vol. 98, no. 3, pp. 387-391, 2007.

[278] N. Kato, M. Toukairin, I. Asanuma, and T. Motoyama, "Immunocytochemistry for hepatocyte nuclear factor- $1 \beta$ (HNF-11 ): a marker for ovarian clear cell carcinoma," Diagnostic Cytopathology, vol. 35, no. 4, pp. 193-197, 2007.

[279] A. Tsuchiya, M. Sakamoto, J. Yasuda et al., "Expression profiling in ovarian clear cell carcinoma: identification of hepatocyte nuclear factor- $1 \beta$ as a molecular marker and a possible molecular target for therapy of ovarian clear cell carcinoma," American Journal of Pathology, vol. 163, no. 6, pp. 2503-2512, 2003.

[280] K. Yamaguchi, M. Mandai, T. Oura et al., "Identification of an ovarian clear cell carcinoma gene signature that reflects inherent disease biology and the carcinogenic processes," Oncogene, vol. 29, no. 12, pp. 1741-1752, 2010.

[281] D. Bouchard, D. Morisset, Y. Bourbonnais, and G. M. Tremblay, "Proteins with whey-acidic-protein motifs and cancer," Lancet Oncology, vol. 7, no. 2, pp. 167-174, 2006.

[282] J. Li, S. Dowdy, T. Tipton et al., "HE4 as a biomarker for ovarian and endometrial cancer management," Expert Review of Molecular Diagnostics, vol. 9, no. 6, pp. 555-566, 2009.

[283] P. H. Anborgh, J. C. Mutrie, A. B. Tuck, and A. F. Chambers, "Pre- and post-translational regulation of osteopontin in cancer," Journal of Cell Communication and Signaling, vol. 5, no. 2, pp. 111-122, 2011.

[284] N. I. F. Johnston, V. K. Gunasekharan, A. Ravindranath, C. O'Connell, P. G. Johnston, and M. K. El-Tanani, "Osteopontin as a target for cancer therapy," Frontiers in Bioscience, vol. 13, no. 11, pp. 4361-4372, 2008.

[285] T. M. Tilli, V. F. Franco, B. K. Robbs et al., "Osteopontin-c splicing isoform contributes to ovarian cancer progression," Molecular Cancer Research, vol. 9, no. 3, pp. 280-293, 2011.

[286] M. Breidenbach, D. T. Rein, M. Everts et al., "Mesothelinmediated targeting of adenoviral vectors for ovarian cancer gene therapy," Gene Therapy, vol. 12, no. 2, pp. 187-193, 2005.

[287] M. J. Yen, C. Y. Hsu, T. L. Mao et al., "Diffuse mesothelin expression correlates with prolonged patient survival in ovarian serous carcinoma," Clinical Cancer Research, vol. 12, no. 3, pp. 827-831, 2006.

[288] N. Ahmed, K. T. Oliva, G. Barker et al., "Proteomic tracking of serum protein isoforms as screening biomarkers of ovarian cancer," Proteomics, vol. 5, no. 17, pp. 4625-4636, 2005. 
[289] R. Saldova, L. Royle, C. M. Radcliffe et al., "Ovarian cancer is associated with changes in glycosylation in both acute-phase proteins and IgG," Glycobiology, vol. 17, no. 12, pp. 13441356, 2007.

[290] B. Ye, D. W. Cramer, S. J. Skates et al., "Haptoglobin- $\alpha$ subunit as potential serum biomarker in ovarian cancer: identification and characterization using proteomic profiling and mass spectrometry," Clinical Cancer Research, vol. 9, no. 8, pp. 2904-2911, 2003.

[291] C. Zhao, L. Annamalai, C. Guo et al., "Circulating haptoglobin is an independent prognostic factor in the sera of patients with epithelial ovarian cancer," Neoplasia, vol. 9, no. 1, pp. 1-7, 2007.

[292] H. Kobayashi, M. Suzuki, N. Kanayama, and T. Terao, "Genetic down-regulation of phosphoinositide 3-kinase by bikunin correlates with suppression of invasion and metastasis in human ovarian cancer HRA cells," Journal of Biological Chemistry, vol. 279, no. 8, pp. 6371-6379, 2004.

[293] H. Kobayashi, M. Suzuki, Y. Tanaka, N. Kanayama, and T. Terao, "A Kunitz-type protease inhibitor, bikunin, inhibits ovarian cancer cell invasion by blocking the calciumdependent transforming growth factor- $\beta 1$ signaling cascade," Journal of Biological Chemistry, vol. 278, no. 10, pp. 77907799, 2003.

[294] H. Kobayashi, T. Yagyu, K. Inagaki et al., "Bikunin plus paclitaxel markedly reduces tumor burden and ascites in mouse model of ovarian cancer," International Journal of Cancer, vol. 110, no. 1, pp. 134-139, 2004.

[295] J. Liu, Q. Guo, B. Chen, Y. Yu, H. Lu, and Y. Y. Li, "Cathepsin $\mathrm{B}$ and its interacting proteins, bikunin and TSRC1, correlate with TNF-induced apoptosis of ovarian cancer cells OV-90," FEBS Letters, vol. 580, no. 1, pp. 245-250, 2006.

[296] H. Matsuzaki, H. Kobayashi, T. Yagyu et al., "Plasma bikunin as a favorable prognostic factor in ovarian cancer," Journal of Clinical Oncology, vol. 23, no. 7, pp. 1463-1472, 2005.

[297] M. Suzuki, H. Kobayashi, Y. Tanaka et al., "Bikunin target genes in ovarian cancer cells identified by microarray analysis," Journal of Biological Chemistry, vol. 278, no. 17, pp. 14640-14646, 2003.

[298] Y. Takei, H. Mizukami, Y. Saga et al., "Overexpression of a hybrid gene consisting of the amino-terminal fragment of urokinase and carboxyl-terminal domain of bikunin suppresses invasion and migration of human ovarian cancer cells in vitro," International Journal of Cancer, vol. 113, no. 1, pp. 54-58, 2005.

[299] Y. Tanaka, H. Kobayashi, M. Suzuki, N. Kanayama, M. Suzuki, and T. Terao, "Upregulation of bikunin in tumorinfiltrating macrophages as a factor of favorable prognosis in ovarian cancer," Gynecologic Oncology, vol. 94, no. 3, pp. 725-734, 2004.

[300] E. Basal, G. Z. Eghbali-Fatourechi, K. R. Kalli et al., "Functional folate receptor alpha is elevated in the blood of ovarian cancer patients," PLoS One, vol. 4, no. 7, Article ID e6292, 2009.

[301] L. M. Cranê, H. J. Arts, M. van Oosten et al., "The effect of chemotherapy on expression of folate receptor-alpha in ovarian cancer," Cell Oncology, 2011.

[302] K. R. Kalli, A. L. Oberg, G. L. Keeney et al., "Folate receptor alpha as a tumor target in epithelial ovarian cancer," Gynecologic Oncology, vol. 108, pp. 619-626, 2008.

[303] J. A. Konner, K. M. Bell-McGuinn, P. Sabbatini et al., "Farletuzumab, a humanized monoclonal antibody against folate receptor $\alpha$, in epithelial ovarian cancer: a phase I study," Clinical Cancer Research, vol. 16, no. 21, pp. 5288-5295, 2010.
[304] I. M. Shih and B. Davidson, "Pathogenesis of ovarian cancer: clues from selected overexpressed genes," Future Oncology, vol. 5, no. 10, pp. 1641-1657, 2009.

[305] R. Lim, M. Lappas, N. Ahmed, M. Permezel, M. A. Quinn, and G. E. Rice, "2D-PAGE of ovarian cancer: analysis of soluble and insoluble fractions using medium-range immobilized pH gradients," Biochemical and Biophysical Research Communications, vol. 406, no. 3, pp. 408-413, 2011.

[306] L. E. Moore, E. T. Fung, M. McGuire et al., "Evaluation of apolipoprotein A1 and posttranslationally modified forms of transthyretin as biomarkers for ovarian cancer detection in an independent study population," Cancer Epidemiology Biomarkers and Prevention, vol. 15, no. 9, pp. 1641-1646, 2006.

[307] V. Nosov, F. Su, M. Amneus et al., "Validation of serum biomarkers for detection of early-stage ovarian cancer," American Journal of Obstetrics and Gynecology, vol. 200, no. 6, pp. 639.e1-639.e5, 2009.

[308] S. S. Abdullah-Soheimi, B. K. Lim, O. H. Hashim, and A. S. Shuib, "Patients with ovarian carcinoma excrete different altered levels of urine CD59, kininogen-1 and fragments of inter-alpha-trypsin inhibitor heavy chain $\mathrm{H} 4$ and albumin," Proteome Science, vol. 8, article no. 58, 2010.

[309] J. Kodama, Y. Miyagi, N. Seki et al., "Serum C-reactive protein as a prognostic factor in patients with epithelial ovarian cancer," European Journal of Obstetrics Gynecology and Reproductive Biology, vol. 82, no. 1, pp. 107-110, 1999.

[310] A. Macciò, P. Lai, M. C. Santona, L. Pagliara, G. B. Melis, and G. Mantovani, "High serum levels of soluble IL-2 receptor, cytokines, and $\mathrm{C}$ reactive protein correlate with impairment of $\mathrm{T}$ cell response in patients with advanced epithelial ovarian cancer," Gynecologic Oncology, vol. 69, no. 3, pp. 248-252, 1998.

[311] A. Macciò, C. Madeddu, D. Massa et al., "Interleukin-6 and leptin as markers of energy metabolicchanges in advanced ovarian cancer patients," Journal of Cellular and Molecular Medicine, vol. 13, no. 9 B, pp. 3951-3959, 2009.

[312] A. Macciò, C. Madeddu, D. Massa et al., "Hemoglobin levels correlate with interleukin-6 levels in patients with advanced untreated epithelial ovarian cancer: role of inflammation in cancer-related anemia," Blood, vol. 106, no. 1, pp. 362-367, 2005.

[313] A. T. Toriola, K. Grankvist, C. B. Agborsangaya, A. Lukanova, M. Lehtinen, and H. -M. Surcel, "Changes in pre-diagnostic serum C-reactive protein concentrations and ovarian cancer risk: a longitudinal study," Annals of Oncology, vol. 22, no. 8, pp. 1916-1921, 2011.

[314] M. Chen, L. M. Chen, C. Y. Lin, and K. X. Chai, "The epidermal growth factor receptor (EGFR) is proteolytically modified by the Matriptase-Prostasin serine protease cascade in cultured epithelial cells," Biochimica et Biophysica Acta, vol. 1783, no. 5, pp. 896-903, 2008.

[315] F. P. Costa, E. L. Batista Junior, A. Zelmanowicz et al., "Prostasin, a potential tumor marker in ovarian cancer-a pilot study," Clinics, vol. 64, no. 7, pp. 641-644, 2009.

[316] S. C. Mok, J. Chao, S. Skates et al., "Prostasin, a potential serum marker for ovarian cancer: identification through microarray technology," Journal of the National Cancer Institute, vol. 93, no. 19, pp. 1458-1464, 2001.

[317] R. Agarwal, T. D'Souza, and P. J. Morin, "Claudin-3 and claudin-4 expression in ovarian epithelial cells enhances invasion and is associated with increased matrix metalloproteinase-2 activity," Cancer Research, vol. 65, no. 16, pp. 7378-7385, 2005. 
[318] T. D’Souza, R. Agarwal, and P. J. Morin, "Phosphorylation of Claudin-3 at threonine 192 by cAMP-dependent protein kinase regulates tight junction barrier function in ovarian cancer cells," Journal of Biological Chemistry, vol. 280, no. 28, pp. 26233-26240, 2005.

[319] B. Davidson, "The diagnostic and molecular characteristics of malignant mesothelioma and ovarian/peritoneal serous carcinoma," Cytopathology, vol. 22, no. 1, pp. 5-21, 2011.

[320] H. Honda, M. J. Pazin, H. Ji, R. P. Wernyj, and P. J. Morin, "Crucial roles of Sp1 and epigenetic modifications in the regulation of the cldn4 promoter in ovarian cancer cells," Journal of Biological Chemistry, vol. 281, no. 30, pp. 21433 21444, 2006.

[321] L. Kleinberg, A. Holth, C. G. Trope, R. Reich, and B. Davidson, "Claudin upregulation in ovarian carcinoma effusions is associated with poor survival," Human Pathology, vol. 39, no. 5, pp. 747-757, 2008.

[322] J. Li, S. Chigurupati, R. Agarwal et al., "Possible angiogenic roles for claudin-4 in ovarian cancer," Cancer Biology and Therapy, vol. 8, no. 19, pp. 1806-1814, 2009.

[323] L. B. A. Rangel, R. Agarwal, T. D'Souza et al., "Tight junction proteins claudin-3 and claudin-4 are frequently overexpressed in ovarian cancer but not in ovarian cystadenomas," Clinical Cancer Research, vol. 9, no. 7, pp. 2567-2575, 2003.

[324] I. Szabó, A. Kiss, Z. Schaff, and G. Sobel, "Claudins as diagnostic and prognostic markers in gynecological cancer," Histology and histopathology, vol. 24, no. 12, pp. 1607-1615, 2009.

[325] M. Turunen, A. Talvensaari-Mattila, Y. Soini, and M. Santala, "Claudin-5 overexpression correlates with aggressive behavior in serous ovarian adenocarcinoma," Anticancer Research, vol. 29, no. 12, pp. 5185-5189, 2009.

[326] X. Yuan, X. Lin, G. Manorek, and S. B. Howell, "Challenges associated with the targeted delivery of gelonin to claudinexpressing cancer cells with the use of activatable cell penetrating peptides to enhance potency," BMC Cancer, vol. 11, p. 61, 2011.

[327] A. Bovicelli, G. D’Andrilli, and A. Giordano, "New players in ovarian cancer," Journal of Cellular Physiology, vol. 226, no. 10, pp. 2500-2504, 2011.

[328] H. P. Beck, T. Kohn, S. Rubenstein et al., "Discovery of potent LPA2 (EDG4) antagonists as potential anticancer agents," Bioorganic and Medicinal Chemistry Letters, vol. 18, no. 3, pp. 1037-1041, 2008.

[329] T. Bese, M. Barbaros, E. Baykara et al., "Comparison of total plasma lysophosphatidic acid and serum CA-125 as a tumor marker in the diagnosis and follow-up of patients with epithelial ovarian cancer," Journal of Gynecologic Oncology, vol. 21, no. 4, pp. 248-254, 2010.

[330] K. U. Choi, J. S. Yun, I. H. Lee et al., "Lysophosphatidic acidinduced expression of periostin in stromal cells: prognoistic relevance of periostin expression in epithelial ovarian cancer," International Journal of Cancer, vol. 128, no. 2, pp. 332$342,2011$.

[331] C. H. Chou, L. H. Wei, M. L. Kuo et al., "Up-regulation of interleukin-6 in human ovarian cancer cell via a Gi/PI3KAkt/NF- $\kappa$ B pathway by lysophosphatidic acid, an ovarian cancer-activating factor," Carcinogenesis, vol. 26, no. 1, pp. 45-52, 2005.

[332] E. S. Jeon, S. C. Heo, I. H. Lee et al., "Ovarian cancer-derived lysophosphatidic acid stimulates secretion of VEGF and stromal cell-derived factor- $1 \alpha$ from human mesenchymal stem cells," Experimental and Molecular Medicine, vol. 42, no. 4, pp. 280-293, 2010.
[333] E. K. Kim, J. M. Park, S. Lim et al., "Activation of AMPactivated protein kinase is essential for lysophosphatidic acid-induced cell migration in ovarian cancer cells," Journal of Biological Chemistry, vol. 286, no. 27, pp. 24036-24045, 2011.

[334] M. Murph, T. Tanaka, S. Liu, and G. B. Mills, "Of spiders and crabs: the emergence of lysophospholipids and their metabolic pathways as targets for therapy in cancer," Clinical Cancer Research, vol. 12, no. 22, pp. 6598-6602, 2006.

[335] R. A. Oyesanya, S. Greenbaum, D. Dang et al., "Differential requirement of the epidermal growth factor receptor for $\mathrm{G}$ protein-mediated activation of transcription factors by lysophosphatidic acid," Molecular Cancer, vol. 9, article no. 8,2010

[336] N. A. Said, I. Najwer, M. J. Socha, D. J. Fulton, S. C. Mok, and K. Motamed, "SPARC inhibits LPA-mediated mesothelialovarian cancer cell crosstalk," Neoplasia, vol. 9, no. 1, pp. 2335, 2007.

[337] I. Sedláková, J. Vávrová, J. Tošner, and L. Hanousek, "Lysophosphatidic acid (LPA)—a perspective marker in ovarian cancer," Tumor Biology, vol. 32, no. 2, pp. 311-316, 2011.

[338] J. H. Seo, K. J. Jeong, W. J. Oh et al., "Lysophosphatidic acid induces STAT3 phosphorylation and ovarian cancer cell motility: their inhibition by curcumin," Cancer Letters, vol. 288, no. 1, pp. 50-56, 2010.

[339] S. Yu, M. M. Murph, Y. Lu et al., "Lysophosphatidic acid receptors determine tumorigenicity and aggressiveness of ovarian cancer cells," Journal of the National Cancer Institute, vol. 100, no. 22, pp. 1630-1642, 2008.

[340] K. L. Abbott, J. M. Lim, L. Wells, B. B. Benigno, J. F. McDonald, and M. Pierce, "Identification of candidate biomarkers with cancerspecific glycosylation in the tissue and serum of endometrioid ovarian cancer patients by glycoproteomic analysis," Proteomics, vol. 10, no. 3, pp. 470-481, 2010.

[341] B. N. Misa, Z. Gengyin, L. Yaqiong et al., "Novel isoforms of periostin expressed in the human thyroid," Japanese Clinical Medicine, vol. 1, pp. 13-20, 2010.

[342] L. Gillan, D. Matei, D. A. Fishman, C. S. Gerbin, B. Y. Karlan, and D. D. Chang, "Periostin secreted by epithelial ovarian carcinoma is a ligand for $\alpha \mathrm{V} \beta 3$ and $\alpha \mathrm{V} \beta 5$ integrins and promotes cell motility," Cancer Research, vol. 62, no. 18, pp. 5358-5364, 2002.

[343] K. Ruan, S. Bao, and G. Ouyang, "The multifaceted role of periostin in tumorigenesis," Cellular and Molecular Life Sciences, vol. 66, no. 14, pp. 2219-2230, 2009.

[344] M. Zhu, M. S. Fejzo, L. Anderson et al., "Periostin promotes ovarian cancer angiogenesis and metastasis," Gynecologic Oncology, vol. 119, no. 2, pp. 337-344, 2010.

[345] M. Zhu, R. E. Saxton, L. Ramos et al., "Neutralizing monoclonal antibody to periostin inhibits ovarian tumor growth and metastasis," Molecular Cancer Therapeutics, vol. 10, no. 8, pp. 1500-1508, 2011.

[346] E. Bandiera, L. Zanotti, E. Bignotti et al., "Human kallikrein 5: an interesting novel biomarker in ovarian cancer patients that elicits humoral response," International Journal of Gynecological Cancer, vol. 19, no. 6, pp. 1015-1021, 2009.

[347] J. Batra, O. L. Tan, T. O’Mara et al., "Kallikrein-related peptidase 10 (KLK10) expression and single nucleotide polymorphisms in ovarian cancer survival," International Journal of Gynecological Cancer, vol. 20, no. 4, pp. 529-536, 2010.

[348] J. Bayani, M. Paliouras, C. Planque et al., "Impact of cytogenetic and genomic aberrations of the kallikrein locus 
in ovarian cancer," Molecular Oncology, vol. 2, no. 3, pp. 250260, 2008.

[349] C. A. Borgoño, T. Kishi, A. Scorilas et al., "Human kallikrein 8 protein is a favorable prognostic marker in ovarian cancer," Clinical Cancer Research, vol. 12, no. 5, pp. 1487-1493, 2006.

[350] N. Emami and E. P. Diamandis, "Human tissue kallikreins: a road under construction," Clinica Chimica Acta, vol. 381, no. 1, pp. 78-84, 2007.

[351] S. C.L. Koh, K. Razvi, Y. H. Chan et al., "The association with age, human tissue kallikreins 6 and 10 and hemostatic markers for survival outcome from epithelial ovarian cancer," Archives of Gynecology and Obstetrics, vol. 284, no. 1, pp. 183190, 2011.

[352] P. Kountourakis, A. Psyrri, A. Scorilas et al., "Prognostic value of kallikrein-related peptidase 6 protein expression levels in advanced ovarian cancer evaluated by automated quantitative analysis (AQUA)," Cancer Science, vol. 99, no. 11, pp. 2224-2229, 2008.

[353] P. Kountourakis, A. Psyrri, A. Scorilas et al., "Expression and prognostic significance of kallikrein-related peptidase 8 protein levels in advanced ovarian cancer by using automated quantitative analysis," Thrombosis and Haemostasis, vol. 101, no. 3, pp. 541-546, 2009.

[354] U. Kuzmanov, N. Jiang, C. R. Smith, A. Soosaipillai, and E. P. Diamandis, "Differential N-glycosylation of kallikrein 6 derived from ovarian cancer cells or the central nervous system," Molecular \& Cellular Proteomics, vol. 8, no. 4, pp. 791-798, 2009.

[355] L. Y. Luo, S. J. C. Shan, M. B. Elliott, A. Soosaipillai, and E. P. Diamandis, "Purification and characterization of human kallikrein 11, a candidate prostate and ovarian cancer biomarker, from seminal plasma," Clinical Cancer Research, vol. 12, no. 3, pp. 742-750, 2006.

[356] L. Y. Luo, A. Soosaipillai, L. Grass, and E. P. Diamandis, "Characterization of human kallikreins 6 and 10 in ascites fluid from ovarian cancer patients," Tumor Biology, vol. 27, no. 5, pp. 227-234, 2006.

[357] K. Oikonomopoulou, I. Batruch, C. R. Smith, A. Soosaipillai, E. P. Diamandis, and M. D. Hollenberg, "Functional proteomics of kallikrein-related peptidases in ovarian cancer ascites fluid," Biological Chemistry, vol. 391, no. 4, pp. 381390, 2010.

[358] K. Oikonomopoulou, A. Scorilas, I. P. Michael et al., "Kallikreins as markers of disseminated tumour cells in ovarian cancer-a pilot study," Tumor Biology, vol. 27, no. 2, pp. 104114, 2006.

[359] P. Prezas, M. J. E. Arlt, P. Viktorov et al., "Overexpression of the human tissue kallikrein genes KLK4, 5, 6, and 7 increases the malignant phenotype of ovarian cancer cells," Biological Chemistry, vol. 387, no. 6, pp. 807-811, 2006.

[360] S. J. C. Shan, A. Scorilas, D. Katsaros, and E. P. Diamandis, "Transcriptional upregulation of human tissue kallikrein 6 in ovarian cancer: clinical and mechanistic aspects," British Journal of Cancer, vol. 96, no. 2, pp. 362-372, 2007.

[361] S. J. C. Shan, A. Scorilas, D. Katsaros, I. Rigault De La Longrais, M. Massobrio, and E. P. Diamandis, "Unfavorable prognostic value of human kallikrein 7 quantified by ELISA in ovarian cancer cytosols," Clinical Chemistry, vol. 52, no. 10, pp. 1879-1886, 2006.

[362] I. M. Shih, R. Salani, M. Fiegl et al., "Ovarian cancer specific kallikrein profile in effusions," Gynecologic Oncology, vol. 105, no. 2, pp. 501-507, 2007.

[363] N. M. A. White, T. F. F. Chow, S. Mejia-Guerrero et al., "Three dysregulated miRNAs control kallikrein 10 expression and cell proliferation in ovarian cancer," British Journal of Cancer, vol. 102, no. 8, pp. 1244-1253, 2010.

[364] N. M. A. White, M. Mathews, G. M. Yousef et al., "Human kallikrein related peptidases 6 and 13 in combination with CA125 is a more sensitive test for ovarian cancer than CA125 alone," Cancer Biomarkers, vol. 5, no. 6, pp. 279-287, 2009.

[365] G. M. Yousef and E. P. Diamandis, "The human kallikrein gene family: new biomarkers for ovarian cancer," Cancer Treatment and Research, vol. 149, pp. 165-187, 2009.

[366] T. A. Edgell, D. L. Barraclough, A. Rajic et al., "Increased plasma concentrations of anterior gradient 2 protein are positively associated with ovarian cancer," Clinical Science, vol. 118, no. 12, pp. 717-725, 2010.

[367] G. E. Rice, T. A. Edgell, and D. J. Autelitano, "Evaluation of midkine and anterior gradient 2 in a multimarker panel for the detection of ovarian cancer," Journal of Experimental and Clinical Cancer Research, vol. 29, no. 1, article no. 62, 2010.

[368] Z. Wang, Y. Hao, and A. W. Lowe, "The adenocarcinomaassociated antigen, AGR2, promotes tumor growth, cell migration, and cellular transformation," Cancer Research, vol. 68 , no. 2, pp. 492-497, 2008.

[369] N. S. Anderson, Y. Bermudez, D. Badgwell et al., "Urinary levels of Bcl-2 are elevated in ovarian cancer patients," Gynecologic Oncology, vol. 112, no. 1, pp. 60-67, 2009.

[370] P. Chaudhry, R. Srinivasan, and F. D. Patel, "Expression of the major fas family and Bcl-2 family of proteins in epithelial ovarian cancer (EOC) and their correlation to chemotherapeutic response and outcome," Oncology Research, vol. 18, no. 11-12, pp. 549-559, 2010.

[371] R. Brunmeir, S. Lagger, and C. Seiser, "Histone deacetylase 1 and 2-controlled embryonic development and cell differentiation," International Journal of Developmental Biology, vol. 53, no. 2-3, pp. 275-289, 2009.

[372] K. C. Chao, C. C. Chang, M. S. Yen, and P. H. Wang, "Anti-tumor activity of histone deacetylase inhibitors and the effect on ATP-binding cassette in ovarian carcinoma cells," European Journal of Gynaecological Oncology, vol. 31, no. 4, pp. 402-410, 2010.

[373] C. Conti, E. Leo, G. S. Eichler et al., "Inhibition of histone deacetylase in cancer cells slows down replication forks, activates dormant origins, and induces DNA damage," Cancer Research, vol. 70, no. 11, pp. 4470-4480, 2010.

[374] M. Haberland, R. L. Montgomery, and E. N. Olson, "The many roles of histone deacetylases in development and physiology: implications for disease and therapy," Nature Reviews Genetics, vol. 10, no. 1, pp. 32-42, 2009.

[375] A. Hayashi, A. Horiuchi, N. Kikuchi et al., "Type-specific roles of histone deacetylase (HDAC) overexpression in ovarian carcinoma: HDACl enhances cell proliferation and HDAC3 stimulates cell migration with downregulation of Ecadherin," International Journal of Cancer, vol. 127, no. 6, pp. 1332-1346, 2010.

[376] H. S. Jeon, M. Y. Ahn, J. H. Park et al., "Anticancer effects of the MHY218 novel hydroxamic acid-derived histone deacetylase inhibitor in human ovarian cancer cells," International Journal of Oncology, vol. 37, no. 2, pp. 419-428, 2010.

[377] A. A. Lane and B. A. Chabner, "Histone deacetylase inhibitors in cancer therapy," Journal of Clinical Oncology, vol. 27, no. 32, pp. 5459-5468, 2009.

[378] Y. Luo, W. Jian, D. Stavreva et al., "Trans-regulation of histone deacetylase activities through acetylation," Journal of Biological Chemistry, vol. 284, no. 50, pp. 34901-34910, 2009. 
[379] X. Ma, H. H. Ezzeldin, and R. B. Diasio, "Histone deacetylase inhibitors: current status and overview of recent clinical trials," Drugs, vol. 69, no. 14, pp. 1911-1934, 2009.

[380] P. A. Marks and W. S. Xu, "Histone deacetylase inhibitors: potential in cancer therapy," Journal of Cellular Biochemistry, vol. 107, no. 4, pp. 600-608, 2009.

[381] S. Chiocca and C. V. Segré, "Regulating the regulators: the post-translational code of class i HDAC1 and HDAC2," Journal of Biomedicine and Biotechnology, vol. 2011, Article ID 690848, 15 pages, 2011.

[382] N. Takai and H. Narahara, "Preclinical studies of chemotherapy using histone deacetylase inhibitors in endometrial cancer," Obstetrics and Gynecology International, vol. 2010, Article ID 923824, 8 pages, 2010.

[383] T. Ueda, N. Takai, M. Nishida, K. Nasu, and H. Narahara, "Apicidin, a novel histone deacetylase inhibitor, has profound anti-growth activity in human endometrial and ovarian cancer cells," International Journal of Molecular Medicine, vol. 19, no. 2, pp. 301-308, 2007.

[384] D. Willis-Martinez, H. W. Richards, N. A. Timchenko, and E. E. Medrano, "Role of HDAC1 in senescence, aging, and cancer," Experimental Gerontology, vol. 45, no. 4, pp. 279$285,2010$.

[385] R. H. Wilting, E. Yanover, M. R. Heideman et al., "Overlapping functions of $\mathrm{Hdac1}$ and Hdac2 in cell cycle regulation and haematopoiesis," EMBO Journal, vol. 29, no. 15, pp. 2586-2597, 2010.

[386] T. Yamaguchi, F. Cubizolles, Y. Zhang et al., "Histone deacetylases 1 and 2 act in concert to promote the G1-to-S progression," Genes and Development, vol. 24, no. 5, pp. 455469, 2010.

[387] C. L. Bartels and G. J. Tsongalis, "Mini-reviews micrornas:novel biomarkers for human cancer," Clinical Chemistry, vol. 55, no. 4, pp. 623-631, 2009.

[388] K. D. Cowden Dahl, R. Dahl, J. N. Kruichak, and L. G. Hudson, "The epidermal growth factor receptor responsive miR-125a represses mesenchymal morphology in ovarian cancer cells," Neoplasia, vol. 11, no. 11, pp. 1208-1215, 2009.

[389] C. J. Creighton, M. D. Fountain, Z. Yu et al., "Molecular profiling uncovers a p53-associated role for microRNA-31 in inhibiting the proliferation of serous ovarian carcinomas and other cancers," Cancer Research, vol. 70, no. 5, pp. 1906-1915, 2010.

[390] Z. Li, S. Hu, J. Wang et al., "MiR-27a modulates MDR1/Pglycoprotein expression by targeting HIPK2 in human ovarian cancer cells," Gynecologic Oncology, vol. 119, no. 1, pp. 125-130, 2010.

[391] J. Lu, G. Getz, E. A. Miska et al., "MicroRNA expression profiles classify human cancers," Nature, vol. 435, no. 7043, pp. 834-838, 2005.

[392] N. Rosenfeld, R. Aharonov, E. Meiri et al., "MicroRNAs accurately identify cancer tissue origin," Nature Biotechnology, vol. 26, no. 4, pp. 462-469, 2008.

[393] A. Sorrentino, C. G. Liu, A. Addario, C. Peschle, G. Scambia, and C. Ferlini, "Role of microRNAs in drug-resistant ovarian cancer cells," Gynecologic Oncology, vol. 111, no. 3, pp. 478486, 2008.

[394] H. Yang, W. Kong, L. He et al., "MicroRNA expression profiling in human ovarian cancer: miR-214 induces cell survival and cisplatin resistance by targeting PTEN," Cancer Research, vol. 68, no. 2, pp. 425-433, 2008.

[395] N. Yang, S. Kaur, S. Volinia et al., "MicroRNA microarray identifies Let-7i as a novel biomarker and therapeutic target in human epithelial ovarian cancer," Cancer Research, vol. 68, no. 24, pp. 10307-10314, 2008.

[396] L. Zhang, S. Volinia, T. Bonome et al., "Genomic and epigenetic alterations deregulate microRNA expression in human epithelial ovarian cancer," Proceedings of the National Academy of Sciences of the United States of America, vol. 105, no. 19, pp. 7004-7009, 2008.

[397] J. LoPiccolo, G. M. Blumenthal, W. B. Bernstein, and P. A. Dennis, "Targeting the PI3K/Akt/mTOR pathway: effective combinations and clinical considerations," Drug Resistance Updates, vol. 11, no. 1-2, pp. 32-50, 2008.

[398] D. A. Altomare, Q. W. Hui, K. L. Skele et al., "AKT and mTOR phosphorylation is frequently detected in ovarian cancer and can be targeted to disrupt ovarian tumor cell growth," Oncogene, vol. 23, no. 34, pp. 5853-5857, 2004.

[399] P. Dent, S. Grant, P. B. Fisher, and D. T. Curiel, "PI3K: a rational target for ovarian cancer therapy?" Cancer Biology and Therapy, vol. 8, no. 1, pp. 27-30, 2009.

[400] X. Fan, D. D. Ross, H. Arakawa, V. Ganapathy, I. Tamai, and T. Nakanishi, "Impact of system L amino acid transporter 1 (LAT1) on proliferation of human ovarian cancer cells: a possible target for combination therapy with anti-proliferative aminopeptidase inhibitors," Biochemical Pharmacology, vol. 80, no. 6, pp. 811-818, 2010.

[401] M. Harasawa, M. Yasuda, T. Hirasawa et al., "Analysis of mTOR inhibition-involved pathway in ovarian clear cell adenocarcinoma," Acta Histochemica et Cytochemica, vol. 44, no. 2, pp. 113-118, 2011.

[402] R. Rattan, S. Giri, L. C. Hartmann, and V. Shridhar, "Metformin attenuates ovarian cancer cell growth in an AMPkinase dispensable manner," Journal of Cellular and Molecular Medicine, vol. 15, no. 1, pp. 166-178, 2011.

[403] X. B. Trinh, P. A. Van Dam, L. Y. Dirix, P. B. Vermeulen, and W. A. A. Tjalma, "The rationale for mTOR inhibition in epithelial ovarian cancer," Expert Opinion on Investigational Drugs, vol. 18, no. 12, pp. 1885-1891, 2009.

[404] S. Arao, H. Suwa, M. Mandai et al., "Expression of multidrug resistance gene and localization of P- glycoprotein in human primary ovarian cancer," Cancer Research, vol. 54, no. 5, pp. 1355-1359, 1994.

[405] H. Gréen, P. Söderkvist, P. Rosenberg, G. Horvath, and C. Peterson, "mdr-1 single nucleotide polymorphisms in ovarian cancer tissue: G2677T/A correlates with response to paclitaxel chemotherapy," Clinical Cancer Research, vol. 12, no. 3 I, pp. 854-859, 2006.

[406] A. Richardson and S. B. Kaye, "Drug resistance in ovarian cancer: the emerging importance of gene transcription and spatio-temporal regulation of resistance," Drug Resistance Updates, vol. 8, no. 5, pp. 311-321, 2005.

[407] M. M. Baekelandt, R. Holm, J. M. Nesland, C. G. Tropé, and G. B. Kristensen, "P-glycoprotein expression is a marker for chemotherapy resistance and prognosis in advanced ovarian cancer," Anticancer Research, vol. 20, no. 2 B, pp. 1061-1067, 2000.

[408] G. Chenevix-Trench, S. E. Johnatty, J. Beesley et al., "ABCB1 (MDR 1) polymorphisms and progression-free survival among women with ovarian cancer following paclitaxel/carboplatin chemotherapy," Clinical Cancer Research, vol. 14, no. 17, pp. 5594-5601, 2008.

[409] S. Hille, D. T. Rein, M. Riffelmann et al., "Anticancer drugs induce mdrl gene expression in recurrent ovarian cancer," Anti-Cancer Drugs, vol. 17, no. 9, pp. 1041-1044, 2006. 
[410] Z. Duan, K. A. Brakora, and M. V. Seiden, "Inhibition of ABCB1 (MDR1) and ABCB4 (MDR3) expression by small interfering RNA and reversal resistance in human ovarian cancer cells," Molecular Cancer Therapeutics, vol. 3, no. 7, pp. 833-838, 2004.

[411] H. Xing, S. Wang, D. Weng et al., "Knock-down of P-glycoprotein reverses taxol resistance in ovarian cancer multicellular spheroids," Oncology Reports, vol. 17, no. 1, pp. 117122, 2007.

[412] S. Miettinen, S. Grènman, and T. Ylikomi, "Inhibition of P-glycoprotein-mediated docetaxel efflux sensitizes ovarian cancer cells to concomitant docetaxel and SN-38 exposure," Anticancer Drugs, vol. 20, no. 4, pp. 267-276, 2009.

[413] P. Zahedi, R. de Souza, L. Huynh, M. Piquette-Miller, and C. Allen, "Combination drug delivery strategy for the treatment of multidrug resistant ovarian cancer," Molecular Pharmaceutics, vol. 8, no. 1, pp. 260-269, 2011.

[414] Y. Yang, Z. Wang, M. Li, and S. Lu, "Chitosan/pshRNA plasmid nanoparticles targeting MDR1 gene reverse paclitaxel resistance in ovarian cancer cells," Journal of Huazhong University of Science and Technology, vol. 29, no. 2, pp. 239242, 2009.

[415] D. C. Hiss, G. A. Gabriels, and P. I. Folb, "Combination of tunicamycin with anticancer drugs synergistically enhances their toxicity in multidrug-resistant human ovarian cystadenocarcinoma cells," Cancer Cell International, vol. 7, article no. 5, 2007.

[416] C. Grimm, S. Polterauer, R. Zeillinger et al., "Two multidrugresistance (ABCB1) gene polymorphisms as prognostic parameters in women with ovarian cancer," Anticancer Research, vol. 30, no. 9, pp. 3487-3491, 2010.

[417] A. H. Ludwig and J. Kupryjańczyk, "Does MDR-1 G2677T/A polymorphism really associate with ovarian cancer response to paclitaxel chemotherapy?" Clinical Cancer Research, vol. 12, no. 20, part 1, pp. 6204-6205, 2006.

[418] S. E. Johnatty, J. Beesley, J. Paul et al., "ABCB1 (MDR 1) polymorphisms and progression-free survival among women with ovarian cancer following paclitaxel/carboplatin chemotherapy," Clinical Cancer Research, vol. 14, no. 17, pp. 5594-5601, 2008.

[419] K. Ikeda, K. Sakai, R. Yamamoto et al., "Multivariate analysis for prognostic significance of histologic subtype, GST-pi, MDR-1, and p53 in stages II-IV ovarian cancer," International Journal of Gynecological Cancer, vol. 13, no. 6, pp. 776-784, 2003.

[420] L. Lu, D. Katsaros, A. Wiley, I. A. Rigault De La Longrais, M. Puopolo, and H. Yu, "Expression of MDR1 in epithelial ovarian cancer and its association with disease progression," Oncology Research, vol. 16, no. 8, pp. 395-403, 2007.

[421] K. Matsuo, M. L. Eno, E. H. Ahn et al., "Multidrug resistance gene (MDR-1) and risk of brain metastasis in epithelial ovarian, fallopian tube, and peritoneal cancer," American Journal of Clinical Oncology, vol. 34, no. 5, pp. 488-493, 2010.

[422] C. Peng, X. Zhang, H. Yu, D. Wu, and J. Zheng, "Wnt5a as a predictor in poor clinical outcome of patients and a mediator in chemoresistance of ovarian cancer," International Journal of Gynecological Cancer, vol. 21, no. 2, pp. 280-288, 2011. 


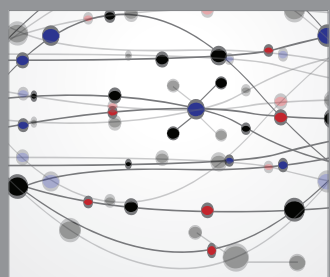

The Scientific World Journal
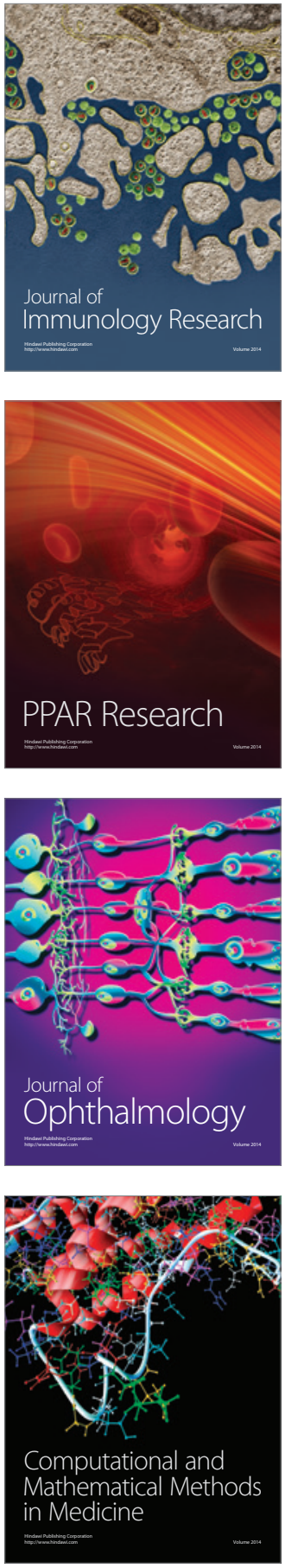

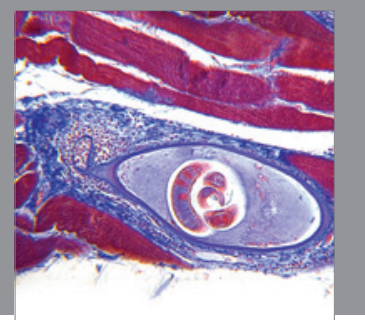

Gastroenterology

Research and Practice
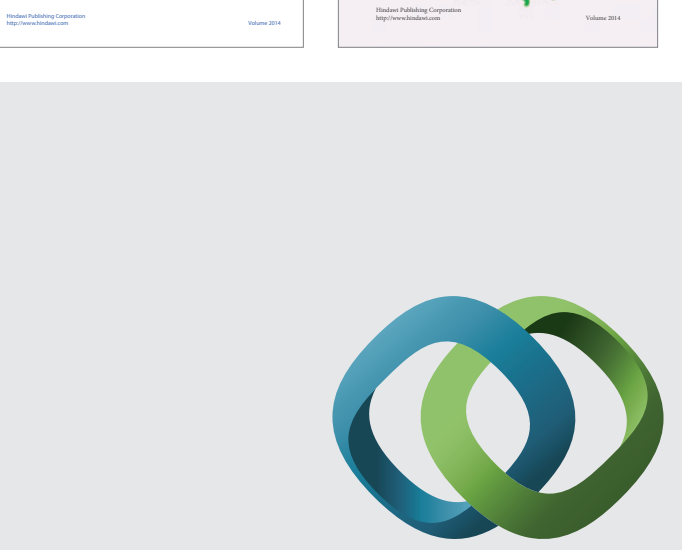

\section{Hindawi}

Submit your manuscripts at

http://www.hindawi.com
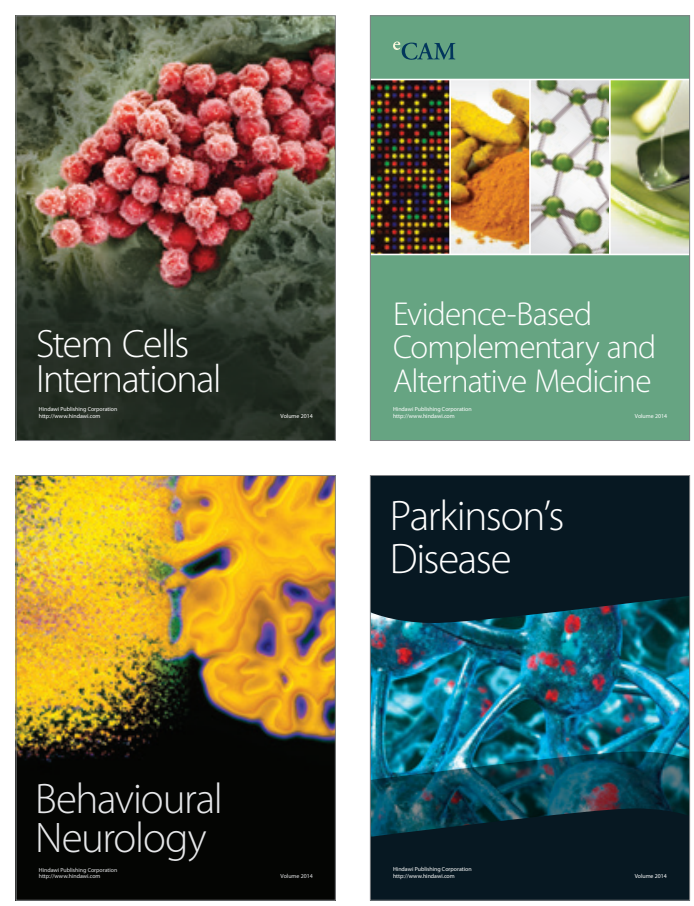

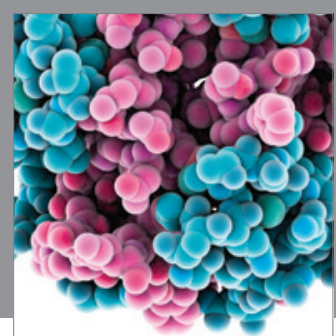

Journal of
Diabetes Research

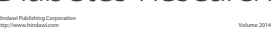

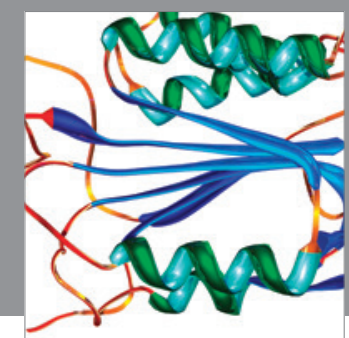

Disease Markers
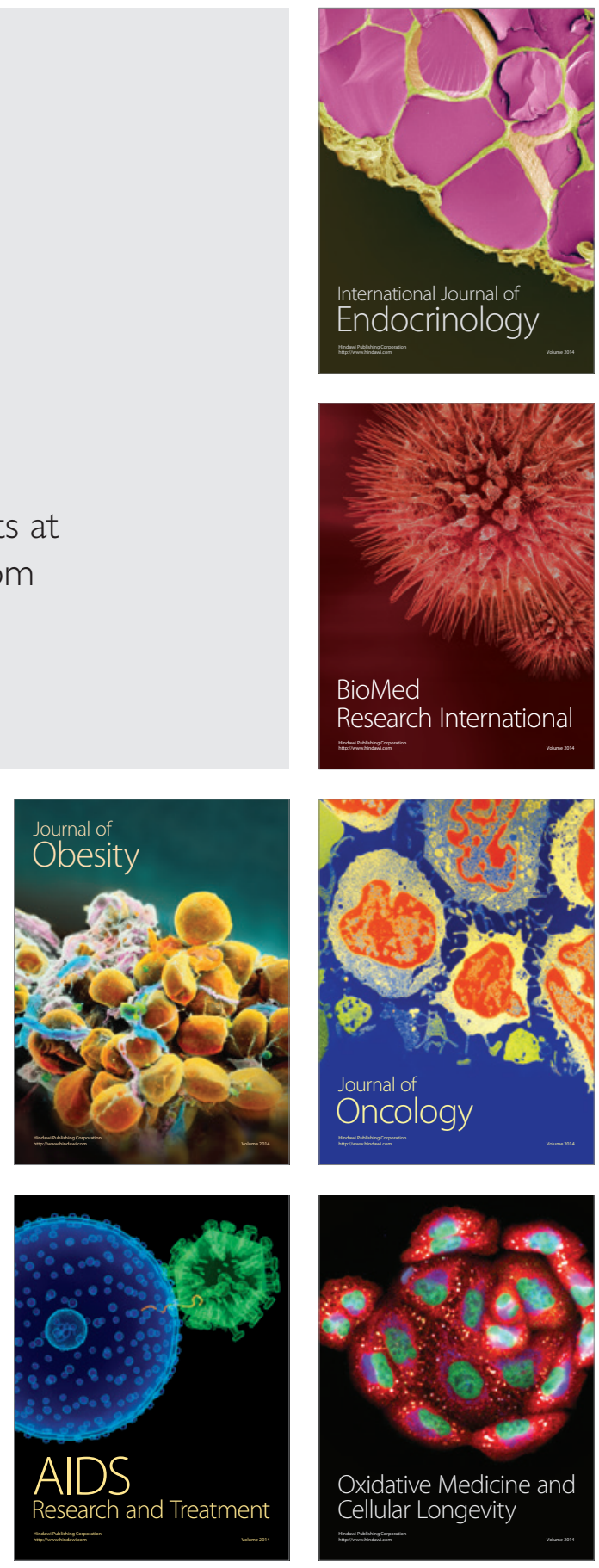